\title{
Article \\ Oblique Wave Attack on Rubble Mound Breakwater Crest Walls of Finite Length
}

\author{
Patricia Mares-Nasarre $1, *(1)$ and Marcel R. A. van Gent ${ }^{2}$ \\ 1 Department of Transportation, Universitat Politècnica de València, 46022 Valencia, Spain \\ 2 Department Coastal Structures \& Waves, Deltares, 2629 Delft, The Netherlands; marcel.vangent@deltares.nl \\ * Correspondence: patmana@cam.upv.es
}

Received: 16 December 2019; Accepted: 25 January 2020; Published: 28 January 2020

\begin{abstract}
Rubble mound breakwaters usually present a crest wall to increase the crest freeboards without a large increase of the consumption of material. Methods in the literature to design crest walls are based on estimates of the wave loads. These methods are focused on the maximum loading that attacks a single position of the crest wall. In practice, crest walls have a finite length. Since the maximum loading does not occur at the same instant over the entire length of the crest wall for oblique waves, these methods overestimate the loading in the situation of oblique waves. Wave loads under oblique wave attack have been measured in physical model tests. A method to account for the effect of the finite length of crest walls has been developed, and design guidelines have been derived. The results of this study in combination with the existing methods in the literature to estimate the wave forces enable a more advanced design of crest walls.
\end{abstract}

Keywords: crown wall; crest wall; oblique waves; rubble mound breakwaters; wave loading; forces

\section{Introduction}

Crest walls are usually built on top of rubble mound breakwaters to achieve higher crest freeboards without a severe increase in the amount of granular material needed. They also protect the crest, improve the accessibility, and provide space for equipment and infrastructure. Crest walls, also called crown walls, are built with concrete and are located on top of the core. During storms, crest walls are impacted by waves, experiencing both (horizontal) forces at the front of the crest wall and (vertical uplift) forces underneath the crest wall. Such wave loads on crest walls determine their size, since crest walls are designed to allow minimal or no displacements under extreme wave conditions. Thus, an accurate prediction of wave loads on crest walls is essential for their design.

Guidelines for crest walls design [1-3] exist, but they are only valid within their range of tested cross sections. In Jacobsen et al. [4], a numerical model is presented to estimate wave loads on the crest walls of rubble mound breakwaters. This model provides valuable estimates of the wave loads for cross-sections that have not been tested before (under perpendicular wave attack). Oblique wave attack has been proven to affect the wave loads on crest walls in [3,5]. Van Gent et al. conducted a systematic study on the reduction of the wave loads on crest walls due to the obliqueness of waves and derived a method to account for such an effect [5].

All the studies related to wave loads on crest walls on rubble mound breakwaters are focused on the (horizontal or vertical) forces that attack the breakwater cross-section (maximum loading). In practice, a crest wall on a rubble mound breakwater has a finite length (e.g., with expansion joints between two parts of the crest wall). If the maximum loading on a single position is used for the entire length of the crest wall, the loading will be overestimated for situations with oblique waves, because the maximum loading does not occur at the same time over the entire length of the crest wall. In other words, methods in the literature assume a rectangle-shaped force diagram all along the crest wall 
length. This means that the actual reduction in the forces on the entire crest wall due to the oblique waves is more significant than simply applying the method proposed by [3,5], which is valid for one position (chainage) along the breakwater. Therefore, this study is focused on the influence of finite length on crest walls under oblique wave attack.

The structure of this paper is as follows. In Section 2, a brief overview of the methods in the literature to estimate wave forces on crest walls is presented. A summary of the findings in [5] is given, since it is the only systematic study found in the literature on the reduction of the wave loads on crest walls due to the oblique wave attack. In Section 3, the physical model tests are described. Here, the tests conducted by [5] in a wave basin are used. In Section 4, the analysis of the tests results is presented. The temporal shape of the force events is described and transformed into the space domain. The actual force that attacks the crest wall is integrated, and a length coefficient is proposed in order to account the force reduction due to the length of the crest wall. Finally, in Section 5, conclusions are drawn.

\section{Oblique Wave Attack on Forces on Rubble Mound Breakwaters Crest Walls}

Sliding is the most common failure mode for crest walls on mound breakwaters. The crest wall is stable when the horizontal force that attacks the structure is lower than the friction resistance, which may be affected by the ascending uplift. The stability of the crest wall for the sliding failure mode is guaranteed by building the crest wall with enough weight. The required size of crest walls is usually determined in physical model tests in wave flumes or wave basins. Before such tests, a first approximation of the needed size of the crest wall must be done by estimating the wave loads. The better the approximation, the shortest the test campaign and the lower the costs. Estimates of wave loads can be obtained from both numerical models and empirical expressions.

An extensive literature exists on methods to estimate forces on crest walls on mound breakwaters. The first approaches were empirical expressions [1,6-12] derived from experimental campaigns. Several proposals $[1,3,5,7,10,12]$ were based on the estimates of virtual wave run-up levels $\left(R u_{2} \%\right)$, which are the wave run-up levels that would be reached in the case of extending the armor layer. More recent methods use numerical models [4] and neural networks estimations [2]. All the mentioned methods except [3] and [5] are based on physical model tests in wave flumes with perpendicular wave attack or the numerical modeling of structures under perpendicular wave attack.

Van Gent et al. [5] was the first systematic study on the effect of oblique waves on the wave loads on crest walls of rubble mound breakwaters. Van Gent et al. [5] conducted physical model tests in a wave basin using wave attack angles $\beta=0^{\circ}, 15^{\circ}, 30^{\circ}, 60,45^{\circ}$, and $75^{\circ}$, where $\beta=0^{\circ}$ corresponds to perpendicular wave attack. Two crest walls geometries (with and without a key) and two wave steepness $\left(s_{m-1,0}=2 \pi H_{s} / g T_{m-1,0}{ }^{2}=0.018\right.$ and 0.048 , which tested $H_{s}$ as the significant wave height and $T_{m-1,0}=m_{-1} / m_{0}$ as the spectral wave period). Van Gent et al. [5] derived new estimators for the horizontal and vertical forces exceeded by $0.1 \%$ of the incoming waves $\left(F_{H, 0.1 \%}\right.$ and $\left.F_{V, 0.1 \%}\right)$ based on $R u_{2 \%}$ (see Equations (1) and (2)).

$$
\begin{gathered}
F_{H, 0.1 \%}=K_{e, H} \rho g H_{\text {wall }}\left(R u_{2 \%}-A_{C}\right) \\
F_{V, 0.1 \%}=K_{e, V} c_{F, v} \rho g B_{\text {wall }}\left(R u_{2 \%}-0.75 A_{C}\right)\left(1-\left[\frac{F_{b}}{A_{C}}\right]^{0.5}\right)
\end{gathered}
$$

where $K_{e, H}=1.6, K_{e, v}$ and $c_{F, v}$ are empirical coefficients, $\rho$ is the density, $g$ is the gravity acceleration, $H_{\text {wall }}$ is the height of the crest wall including the key (if any), $A_{C}$ is the crest level of the armor in front of the crest wall, $B_{\text {wall }}$ is the width of the crest wall including the key (if any), and $F_{b}$ is the level of the bottom of the base plate of the crest wall above the still water level. $K_{e, v}$ was calibrated as a function of the $s_{m-1,0} ; K_{e, v}=2.4$ for $s_{m-1,0}=0.018$; and $K_{e, v}=1.6$ for $s_{m-1,0}=0.048\left(F_{v, 0.1 \%}=\left(2.88-32 s_{o p}\right)\right.$ $F_{v, 2 \%}$, see [3]). $c_{F, v}$ includes the reduction of the vertical forces due to the presence of a key; $c_{F, v}=0.4$ includes those for the crest wall configuration without key, and $c_{F, v}=0.3$ includes those for the crest wall configuration with a key. 
Van Gent et al. [5] included the effect of oblique waves through $R u_{2} \%$. Equation (3) given in $[13,14]$ was proposed to estimate $R u_{2} \%$.

$$
\left\{\begin{array}{l}
\frac{R u_{2 \%} \%}{\gamma_{s}}=c_{0} \xi_{m-1,0} \text { for } \xi_{m-1,0} \leq p \\
\frac{k u_{2} \%}{\gamma H_{s}}=c_{1}-\frac{c_{2}}{\xi_{m-1,0}} \text { for } \xi_{m-1,0} \geq p
\end{array}\right.
$$

where $\gamma=\gamma_{f} \gamma_{\beta}$ is the reduction factor to take into account the effect of both the roughness and the oblique wave attack, respectively, $\xi_{m-1,0}=\tan \alpha /\left(2 \pi H_{s / g} T_{p}^{2}\right)^{0.5}$ is the surf-similarity parameter or Iribarren number, $c_{0}=1.45, c_{1}=5.0, c_{2}=0.25 c_{1}{ }^{2} / c_{0}$, and $p=0.5 c_{1} / c_{0}$. Van Gent et al. [5] used $\gamma_{f}=0.45$ for the double-layer rock armor and proposed a new expression for $\gamma_{\beta}$.

$$
\gamma_{\beta}=0.5 \cos ^{2} \beta+0.5
$$

where $\beta$ is the wave direction at the toe of the structure, where $\beta=0^{\circ}$ corresponds to perpendicular wave attack.

The mentioned methods propose expressions to calculate the maximum wave loading of the crest wall in a single position (chainage) along its length. No methods that incorporate the effect of finite length in the estimation of the wave loading of the crest walls on mound breakwaters are known.

\section{Experimental Methodology}

\subsection{Test Set-Up}

In this study, the tests by [5] are used. Those tests were conducted in the Delta Basin (50 $\mathrm{m} \times$ $50 \mathrm{~m}$ ) at Deltares, Delft. Waves were generated using a multi-directional wave board composed of 100 paddles and equipped with both active absorption and second-order wave steering. This means that the motion of the paddles compensates for the wave reflected by the structure in order to prevent them from re-reflecting on the wave paddles and that the second-order effects of the first lower and higher harmonics of the wave field are considered, ensuring that the generated waves resemble waves that occur in nature.

The experimental set-up in the wave basin is illustrated in Figure 1. A structure with a width of $18.3 \mathrm{~m}$ was built with an angle of $37.5^{\circ}$ between the model and the wave generator. Gravel beaches were built on both sides of the model to ensure wave damping in the basin.

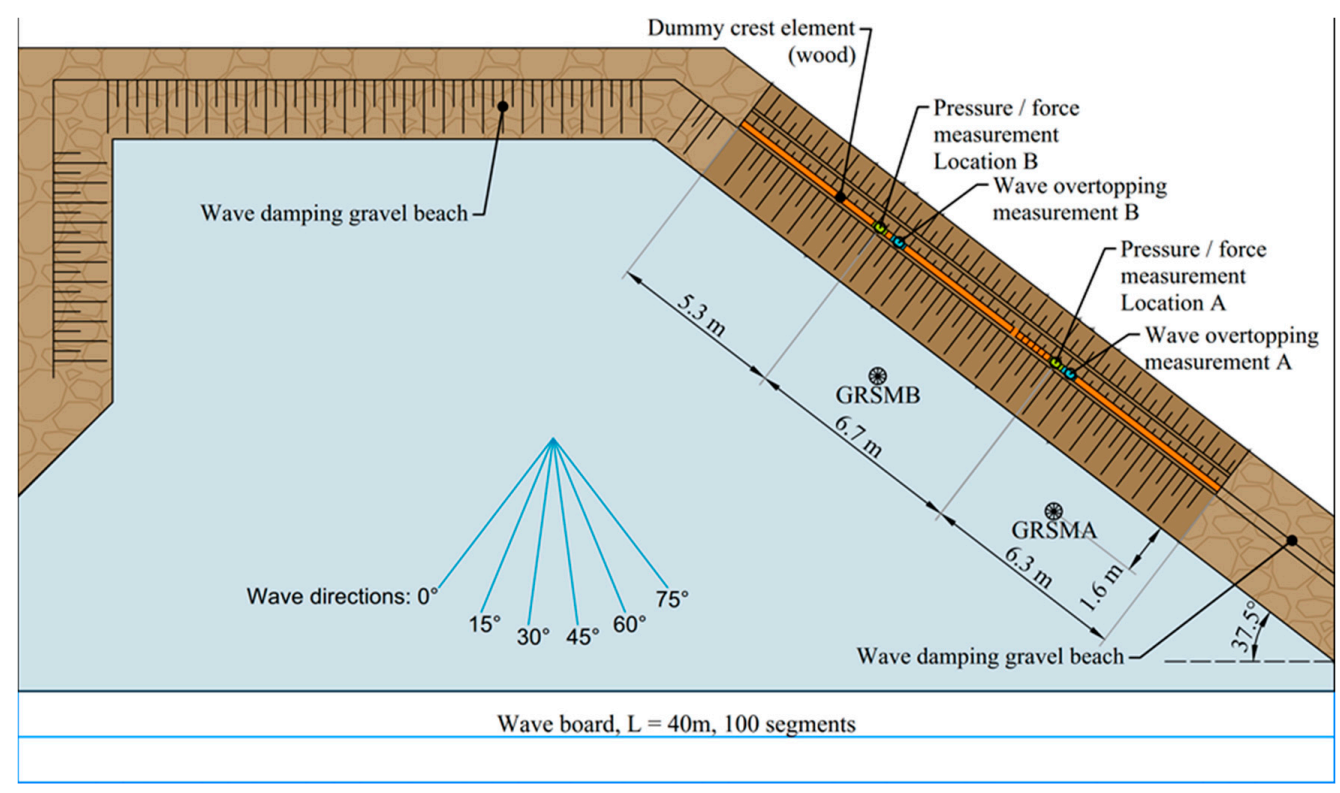

Figure 1. Tests set-up in the wave basin [5]. 
The tested cross-section corresponds to a rubble mound breakwater with 1:2 slope and two crest walls configurations. The model cross-section is depicted in Figure 2. A double-layer rock armor with high density stones $(\Delta=2.69)$ is used in order to limit the armor damage during the tests while keeping a realistic size of the stones. A 1:1.5 slope was used in the rear side of the structure.

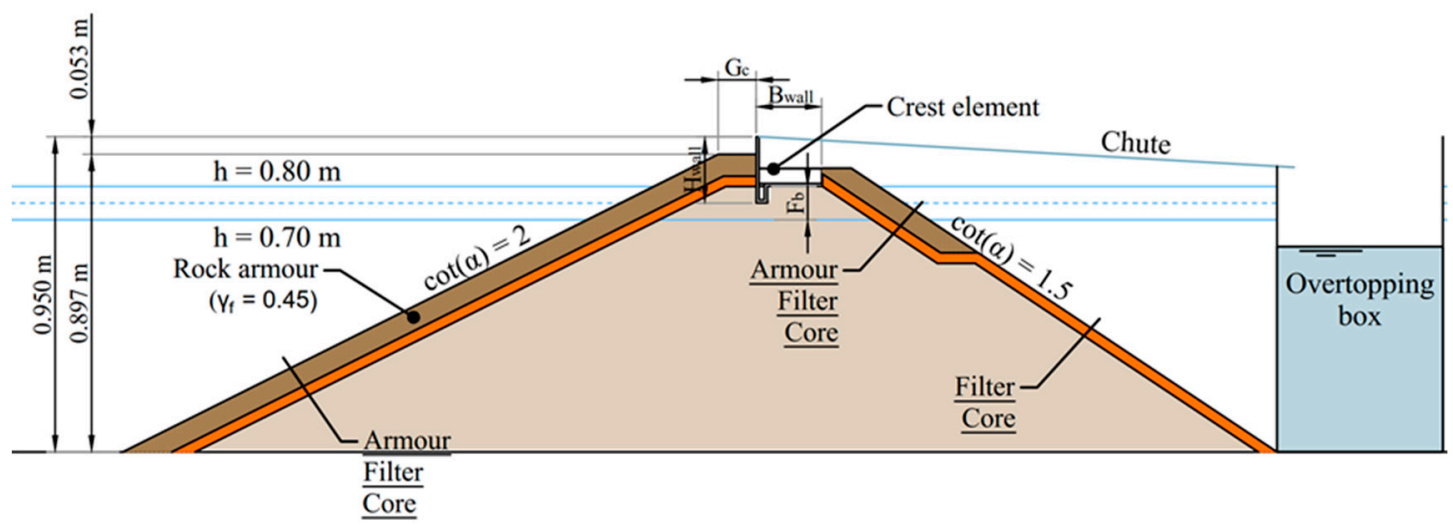

Figure 2. Tested cross-section [5].

Figure 3 presents the two crest wall configurations used in the tests, made of aluminum, as well as the location of the pressure transducers. The two crest walls configurations are identical except for the key placed at the intersection between the front wall and the bottom of the crest wall. The presence of a key is desirable from the geotechnical perspective, since the passive earth pressure is increased. Crest wall A does not present the key, while Crest wall B does. Pressures were measured at the front side of the crest wall and underneath it for both crest wall configurations using 18 pressure transducers. These transducers have a frequency response of $5 \mathrm{kHz}$, an accuracy of $0.06 \%$ of the full scale (Best Straight Line), and a range of $350 \mathrm{mBar}$. In Crest wall A, five pressure transducers were located in the front wall, and three pressure transducers were placed in the baseplate. In Crest wall B, two additional pressure transducers were located: one in the front wall and one in the baseplate. No movement of crest walls was ensured by fixing them to steel frames, as shown in Figure 4.

A:

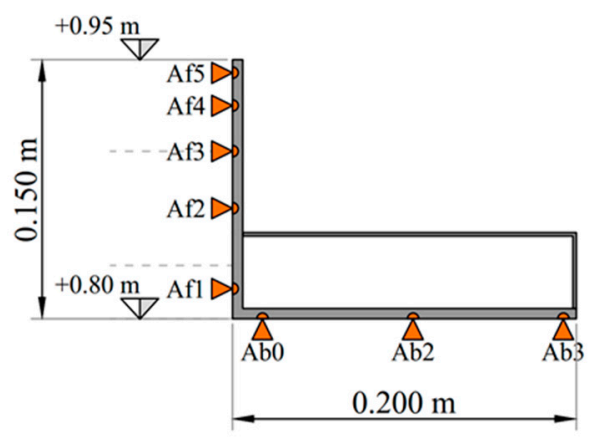

B:

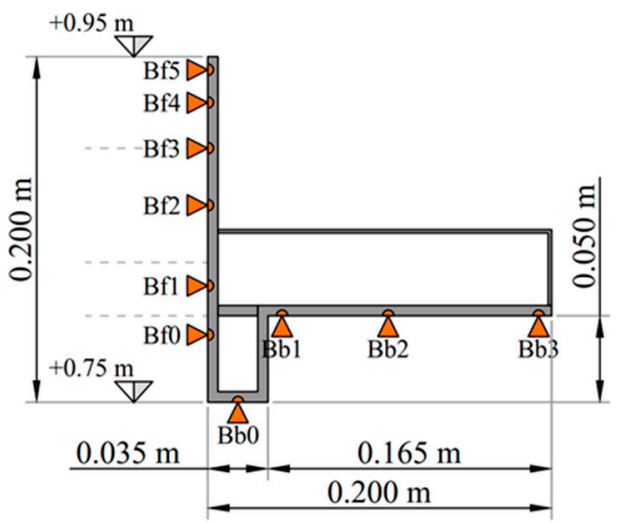

Figure 3. Tested crest wall cross-sections and location of the pressure transducers [5]. 


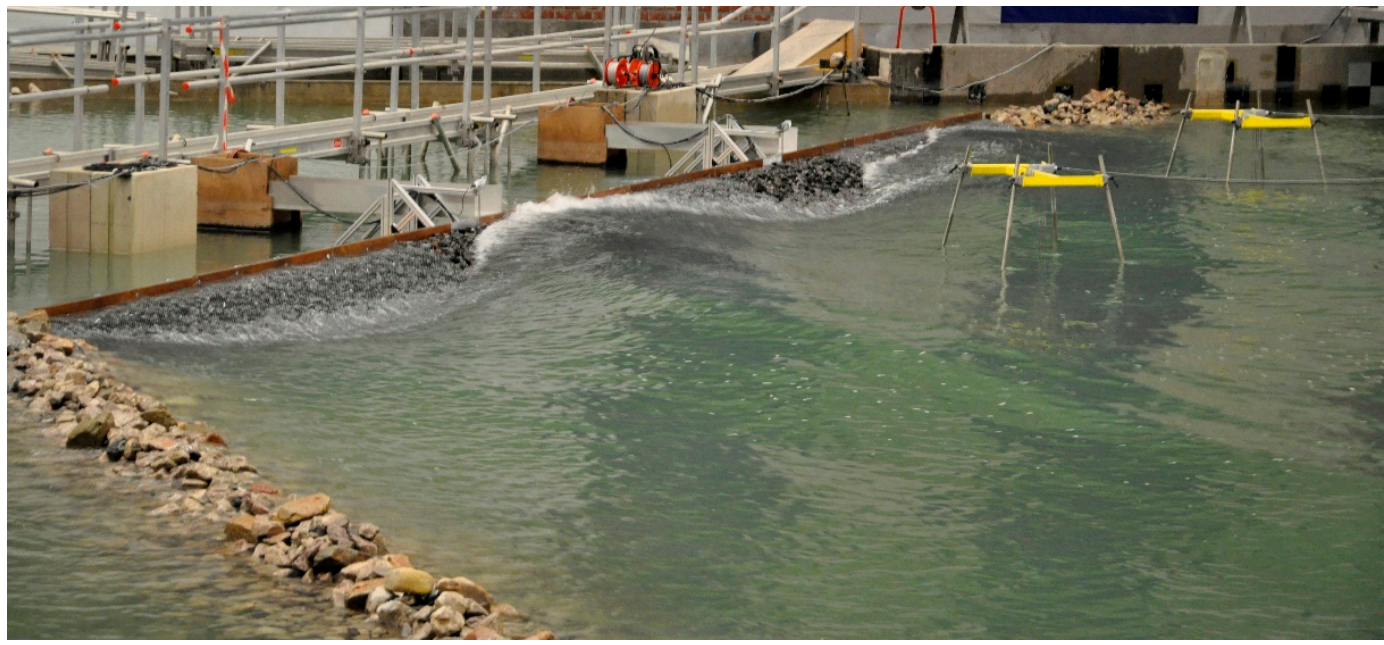

Figure 4. Experimental set-up during a test with oblique waves.

Waves were measured using directional wave gauges (GRSM) at two locations in front of the model so the incident and reflected waves could be separated. The directional wave gauges were located to be in the same line as the measurement cross-sections for a wave angle of $37.5^{\circ}$, which is the average of all the tested angles and perpendicular to the wave paddle (see Figure 1). Small variations observed between both measurement points were accounted for in the following analysis; measurements of GRSM-A were used for Test section A, and measurements of GRSM-B were used for Test section B. In following analysis, incident waves at these locations at the toe were used. The spectral significant wave height $\left(H_{s}=H_{m 0}=4 \sqrt{ } m_{0}\right)$ and the spectral mean wave period $\left(T_{m-1,0}=m_{-1} / m_{0}\right)$ were obtained from the measured wave energy spectra. $T_{m-1,0}$ was first found to better describe the influence of wave energy spectra on wave run-up and overtopping in [13,14]. Later, $T_{m-1,0}$ was applied as the best wave period to describe other interaction processes between waves and coastal structures, see for instance [15]. Thus, this spectral wave period was also used in this study. The mean overtopping discharge was also measured in [5], using two overtopping chutes and boxes (see Figure 5).

Runs of 1000 random waves were generated following a JONSWAP wave spectrum (peak enhancement factor of 3.3). Each configuration was tested with a constant value of $s_{m-1,0}=0.018$ or 0.048. Six wave directions were considered $\beta=0^{\circ}, 15^{\circ}, 30^{\circ}, 60,45^{\circ}$, and $75^{\circ}$, where $\beta=0^{\circ}$ corresponds to the perpendicular wave attack. Three water depths, $h_{s}=0.70,0.75$, and $0.80 \mathrm{~m}$, and crest freeboards, $R_{C}=0.15,0.20$ and $0.25 \mathrm{~m}$, were used. For the lowest $h_{s}$, only the perpendicular waves were tested, since most of the conditions with oblique waves would not have caused forces on the crest walls. In total, 30 tests were used in this study. Table 1 summarizes the main experimental ranges in these tests.

Table 1. Summary of the parameter ranges of the test program.

\begin{tabular}{ccc}
\hline Parameter & Symbol & Value/Range \\
\hline Seaward side slope angle (-) & $\cot \alpha$ & 2 \\
\hline Dimensionless crest freeboard (-) & $R_{c} / H_{s}$ & $0.84-1.60$ \\
\hline Ratio crest level of crest wall and armor $(-)$ & $R_{c} / A_{c}$ & $1.27-1.55$ \\
\hline Dimensionless level of base plate $(-)$ & $F_{b} / H_{S}$ & $0-0.56$ \\
\hline Wave height over water depth ratio $(-)$ & $H_{s} / h_{s}$ & $0.13-0.27$ \\
\hline Surf similarity parameter $(-)$ & $\xi_{m-1,0}$ & 2.3 and 3.7 \\
\hline Number of waves $(-)$ & $N$ & 1000 \\
\hline Wave angles at the toe $\left(^{\circ}\right)$ & $\beta$ & $0-75$ \\
\hline Incident wave height $(\mathrm{m})$ & $H_{s}$ & $0.10-0.19$ \\
\hline
\end{tabular}


Table 1. Cont.

\begin{tabular}{ccc}
\hline Parameter & Symbol & Value/Range \\
\hline Water depth at the toe $(\mathrm{m})$ & $h_{S}$ & $0.70-0.80$ \\
\hline Crest wall freeboard $(\mathrm{m})$ & $R_{C}$ & $0.15-0.25$ \\
\hline Crest level of the armor layer crest $(\mathrm{m})$ & $A_{C}$ & $0.097-0.197$ \\
\hline Crest width of the armor layer $(\mathrm{m})$ & $G_{C}$ & 0.114 \\
\hline Level base plate relative to the wave level $(\mathrm{m})$ & $F_{b}$ & $0-0.10$ \\
\hline Height of the crest wall $(\mathrm{m})$ & $H_{\text {wall }}$ & 0.15 and 0.2 \\
\hline Width of the crest wall $(\mathrm{m})$ & $B_{\text {wall }}$ & 0.20 \\
\hline
\end{tabular}

\subsection{Test Results}

As previously mentioned, 18 pressure transducers were used to measure the pressure signals on the crest walls. Their sampling frequency was $1000 \mathrm{~Hz}$. Before a test, the transducers were set to zero, so the measurements were relative to the pressures caused by the still water level and hydrostatic forces were not included in the measurements. This is especially relevant for Crest wall B, since the key is submerged during the tests with the higher water depth.

Each pressure transducer provided a point of pressure $\left(\mathrm{kN} / \mathrm{m}^{2}\right)$. The pressure distribution along the front and base of the crest wall was obtained by assembling the points of pressure (see Figure 5). The pressure distribution was extrapolated toward the edges of the crest wall. Pressure transducers were located as close as possible to the edges of the crest wall to minimize extrapolation, and the extrapolated pressures were set to a lower limit of 0 . In Figure 6, the extrapolation zone is indicated with blue dashed lines. The pressure distribution was integrated along the front and base of the crown wall to obtain the force on the crest wall. It resulted in a horizontal force on the front of the crest wall $\left(F_{H}\right)$ and a vertical force on its base $\left(F_{V}\right)$.

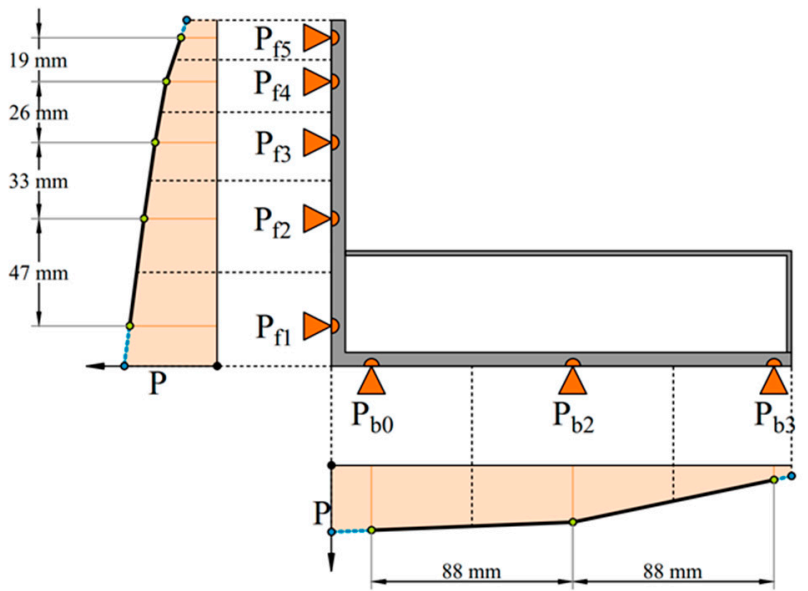

Figure 5. Pressure integration principle [5].

In this study, the temporal shape of the (horizontal and vertical) force events was studied. Thus, the duration of the force events and the time of the peak $\left(t_{\text {peak }}\right)$ was determined. The start, $t_{\text {peak }}$, and end of the force events were determined for both horizontal and vertical forces. They were extracted in three steps: (1) peaks were identified applying the Peaks-Over-Threshold method; in case of two peaks closer than $0.5 \mathrm{~s}$, only the maximum was considered; (2) zero-up and zero-down crossing points were determined using a threshold of 2 to account the points slightly above zero and related to each peak as the start and end points of the force event; and (3) correction was applied in case the start and end points were located even more above zero. If two peaks presented the same start or end point, it was 
replaced by the minimum value between both peaks. The duration is calculated as the difference between the start and end of the force event. The exceedance values used in this study are not based on the total number of force peaks but rather on the number of waves within a test. Note that some vertical force registers were discarded, since the events were too low to be distinguished. Therefore, 59 duration values (29 for Crest wall A + 30 for Crest wall B) were obtained for the horizontal forces, while 47 (22 for Crest wall A + 25 for Crest wall B) were identified for vertical forces. An example of the determination of beginning and ending points is displayed in Figure 6 for vertical forces of Test \#10 on Crest wall A.

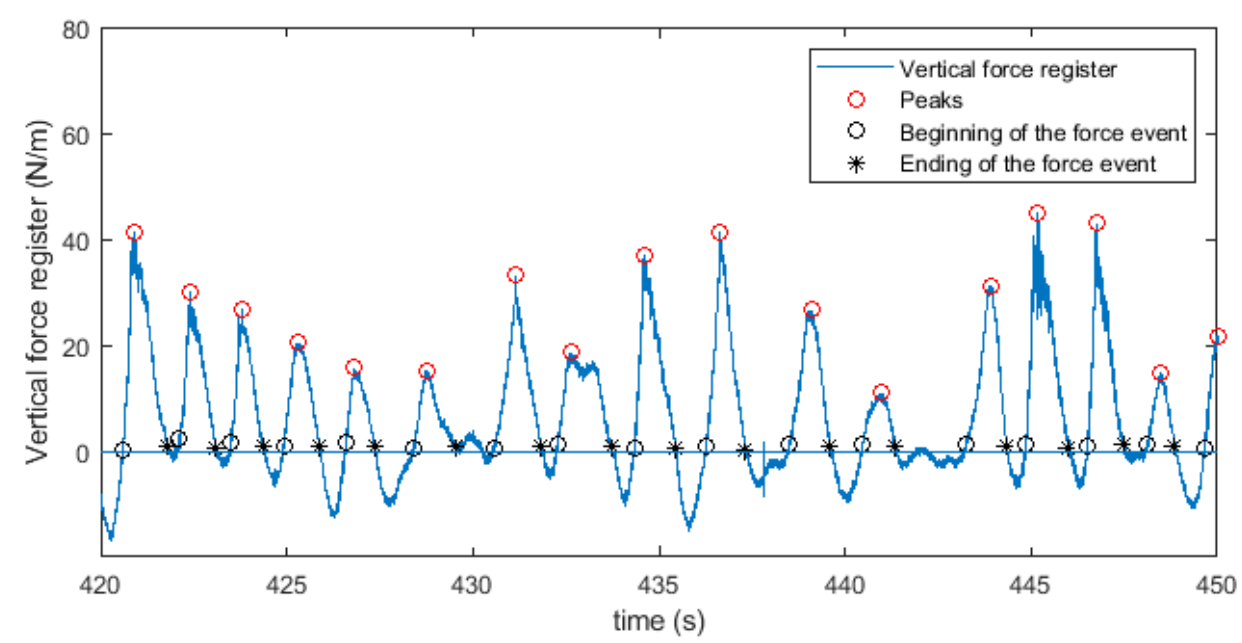

Figure 6. Example of determination of beginning, peak, and ending point for vertical forces of Test \#10 on Crest wall A.

As [5] pointed out, it is common practice to assume that the maximum value registered in tests is the maximum (horizontal or vertical) force, which lasts 1000 waves (force exceeded by $0.1 \%$ of the incoming waves) $[1,2,11]$. However, the smaller the exceedance probability, the more hampered the value is by the coincidence within a test. Thus, Van Gent et al. [5] compared the maximum forces (peak of the force event) within a test (forces exceeded by $0.1 \%$ of the incoming waves) with the forces exceeded by $2 \%$ of the incoming waves. An almost constant ratio was observed for the horizontal forces and for many vertical forces. Here, a similar comparison is conducted for the duration and the position of the peak $\left(t_{\text {peak }}\right)$ to determine whether the force event exceeded by $2 \%$ of the incoming waves is a valid approach to describe the shape of the maximum force events (see Figure 7).

In order to assess the correlation between the variables, the correlation coefficient $(-1 \leq r \leq 1)$ was used. Here, the higher the absolute value of $r$, the higher the correlation.

$$
r=\frac{\sum_{i=1}^{N_{o}}\left(t_{i}-\bar{t}\right)\left(e_{i}-\bar{e}\right)}{\sqrt{\sum_{i=1}^{N_{o}}\left(t_{i}-\bar{t}\right)^{2} \sum_{i=1}^{N_{o}}\left(e_{i}-\bar{e}\right)^{2}}}
$$

where $N_{o}$ is the number of observations, $t_{i}$ are the first variable observations, $e_{i}$ are the corresponding observations of the second variable, and $\bar{t}$ and $\bar{e}$ are the average values of both variables.

As shown in Figure 7 , reasonable correlation $(r=0.790)$ was found for the duration of the horizontal force events exceeded by $0.1 \%$ and $2 \%$ of the incoming waves (duration ${ }_{H, 0.1 \%}$ and duration $_{H, 2} \%$ ). Poor correlation $(0.148 \leq r \leq 0.392)$ was observed for the duration of the vertical force events exceeded by $0.1 \%$ and $2 \%$ of the incoming waves duration $_{V, 0.1 \%}$ and duration $_{V, 2} \%$ ), as well as for the position of the peak (tpeak) of both horizontal and vertical force events exceeded by $2 \%$ and $0.1 \%$ of the incoming waves. As a result, it was decided to conduct the following analysis using the force events exceeded by $0.1 \%$ of the incoming waves. 

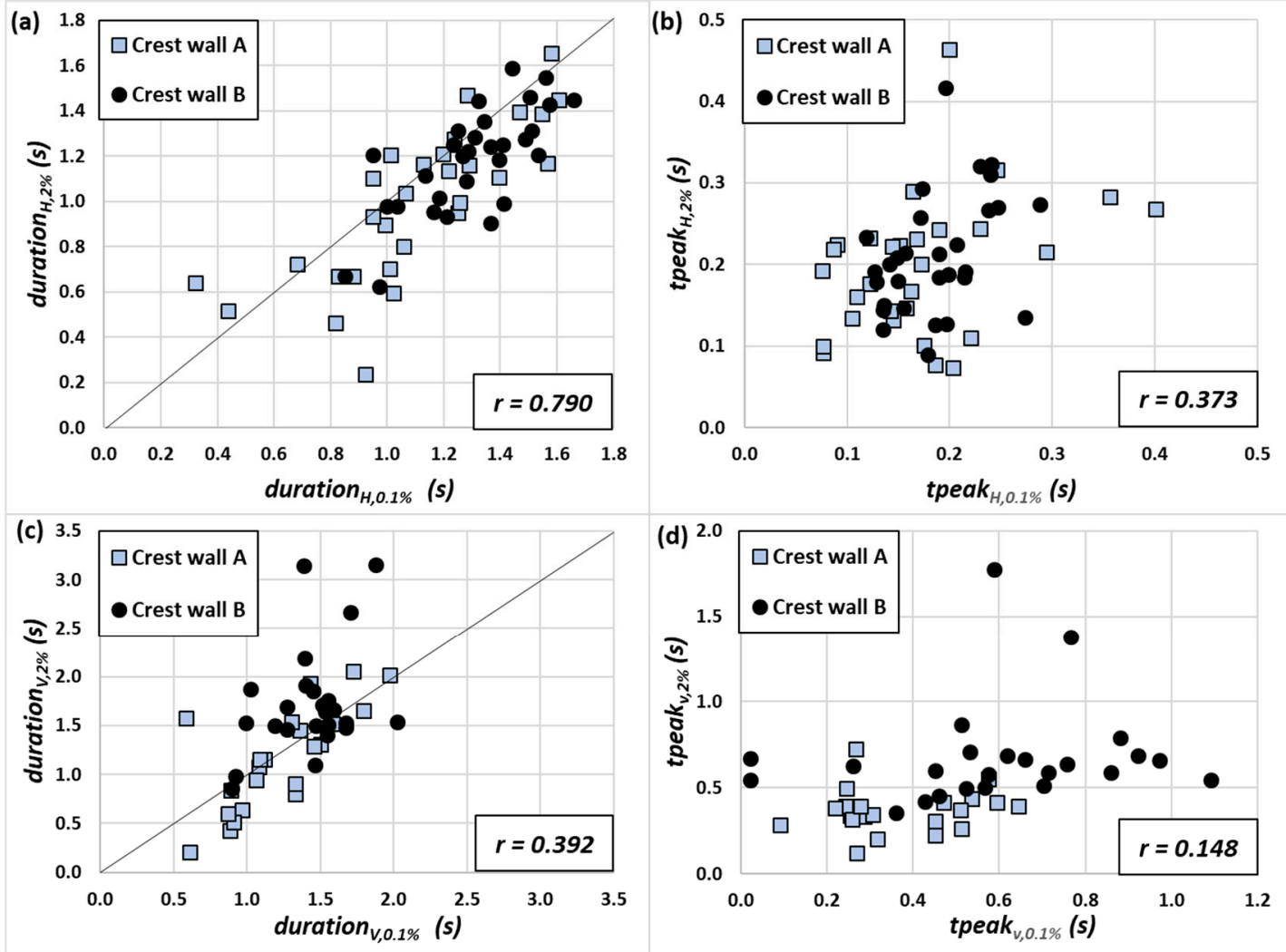

Figure 7. Comparison between: (a) duration of the horizontal force event exceeded by $0.1 \%$ and $2 \%$ of incoming waves (duration $_{H, 0.1 \%}$ and duration ${ }_{H, 2} \%$ ), (b) position of the peak of the horizontal force event exceeded by $0.1 \%$ and $2 \%$ of incoming waves $\left(t_{p e a} k_{H, 0.1 \%}\right.$ and $\left.t p e a k_{H, 2} \%\right)$, (c) duration of the vertical force event exceeded by $0.1 \%$ and $2 \%$ of incoming waves (duration $_{V, 0.1 \%}$ and duration $n_{V, 2} \%$ ), and (d) position of the peak of vertical force event exceeded by $0.1 \%$ and $2 \%$ of incoming waves $\left(t p e a k_{V, 0.1 \%}\right.$ and $t p e a k_{V, 2} \%$ ).

\section{Results}

In this section, the temporal shape of the (horizontal and vertical) force events is discussed. A triangle-shaped model is proposed. Therefore, the base width and the height of that triangle are needed to characterize the temporal shape. The formulas given in [5] are used to estimate the maximum loading (height) for both the horizontal and the vertical forces. Formulas to calculate the duration of the force events and the velocity at which the force events travel along the structure are proposed. This way, the duration is transformed into the space domain (base width); a force diagram along the longitudinal dimension of the crest wall is obtained. This study assumes that the force received by a point of the crest wall in a certain instant is at some point of the spatial force diagram, and the rest of the points receive forces according to the shape of that diagram. The force diagram is integrated to estimate the actual force that attacks the crest wall, including the finite length effect. Such force is compared to the force obtained using the existing methods and a coefficient to account for the effect of finite length on crest walls under oblique wave attack is given.

\subsection{Temporal Shape of Force Events}

In this section, the temporal shape of the force events is discussed and parameterized. In Figure 8, typical registers for horizontal and vertical forces are presented.

In Section 3.2, it was decided to analyze the maximum force event in each test (force events exceeded by $0.1 \%$ of the incoming waves). The maximum force event is extracted for each test, and a new register is created grouping them (Extracted register, from now). A five-second spacing was left 
between the events in order to allow for the afterwards analysis. Figure 9 shows a fragment of such an Extracted register.

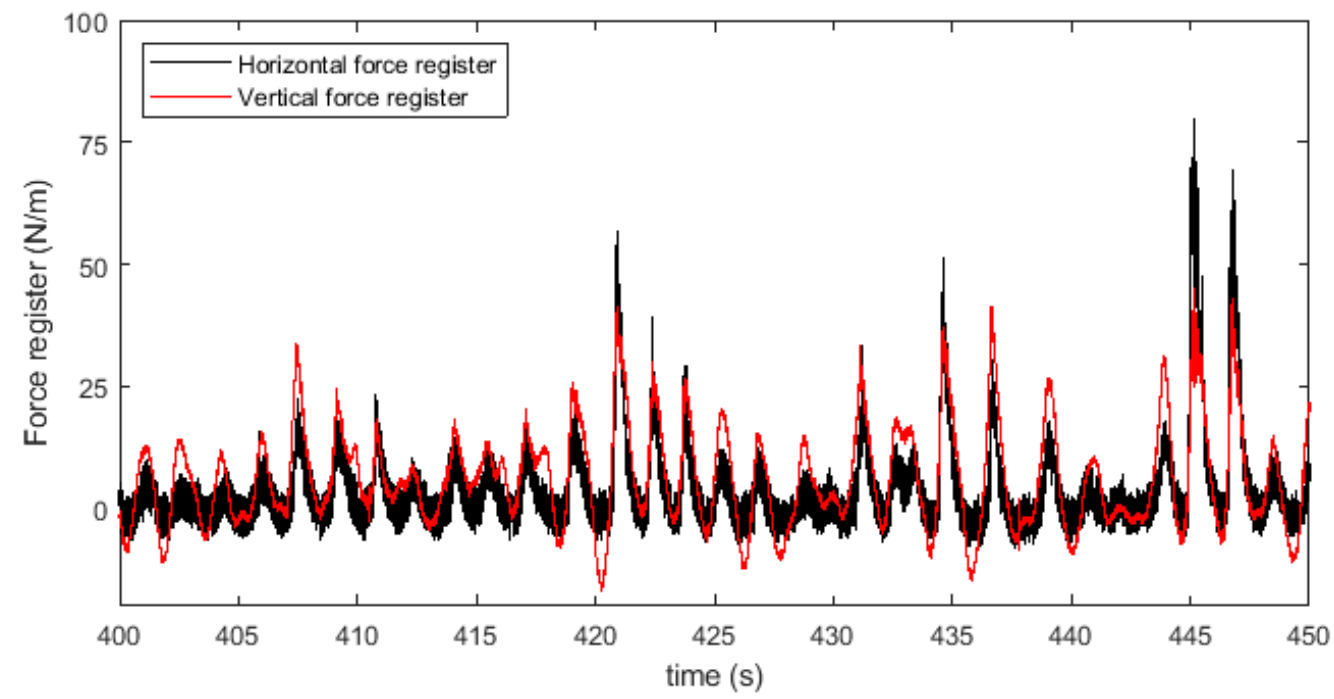

Figure 8. Typical register for horizontal and vertical forces (Test \#10, Crest wall A).

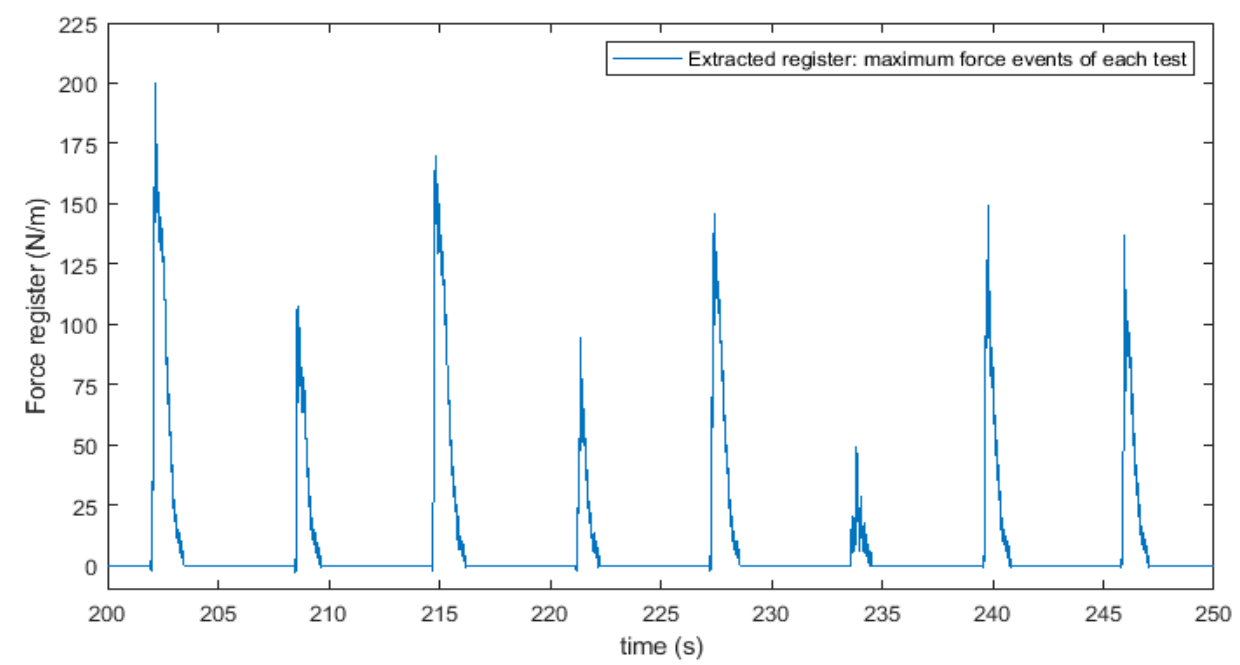

Figure 9. Extracted register made by grouping the maximum force events of each test (horizontal forces).

A triangle-shaped model is proposed for the temporal shape of the force events. In order to assess the goodness of fit of such a model, the correlation between the Extracted register and a new triangle-shaped register is evaluated. The new triangle-shaped register is created using the measured duration and the measured peak values of the forces. The location of the peak value of the force $\left(\right.$ tpeak $\left._{0.1 \%}\right)$ is calculated as function of the duration of the horizontal or vertical force event $\left(\right.$ duration $\left._{0.1 \%}\right)$, as shown in Equation (6).

$$
\text { tpeak }_{0.1 \%}=K_{\text {peak }} \text { duration }_{0.1 \%}
$$

where $K_{\text {peak }}$ is an experimental coefficient. $K_{\text {peak }}$ is calibrated for both horizontal and vertical forces in order to maximize the correlation with the Extracted register. $K_{\text {peak }}=0.1$ and $K_{\text {peak }}=0.35$ are obtained for horizontal and vertical forces, respectively; $0.912 \leq r \leq 0.924$. Figure 10 shows the superposition of the Extracted register (the actual maximum force events) and the triangle-shaped model. 


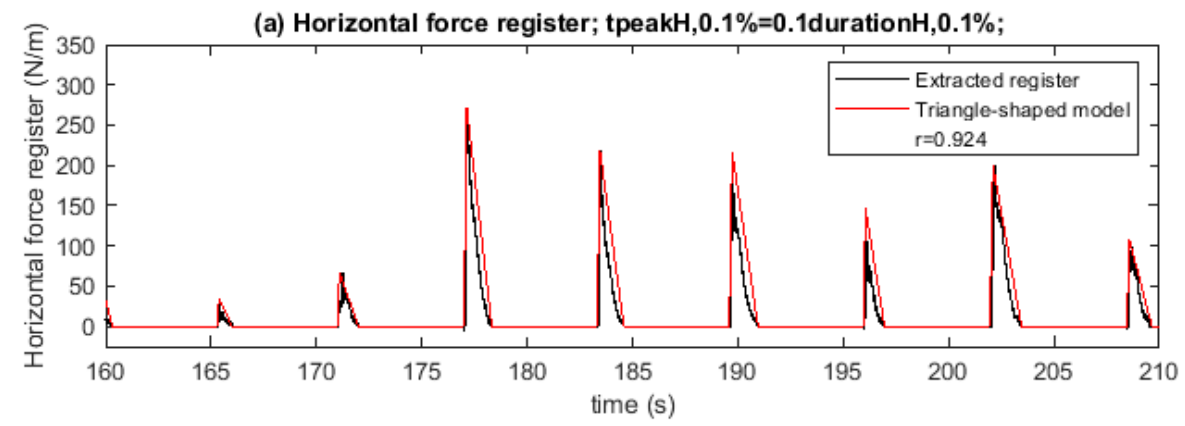

(b) Vertical force register; tpeakV, $0.1 \%=0.35$ durationV, $0.1 \%$;

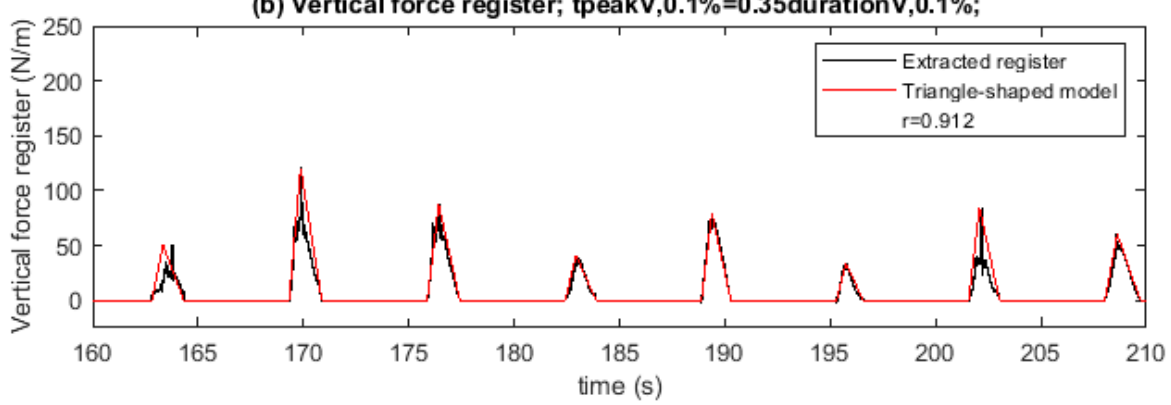

Figure 10. Comparison of Extracted register (the actual maximum force events) and the triangle-shaped model using the measured $F_{H, 0.1 \%}, F_{V, 0.1 \%}$, and duration $0.1 \%$ for: (a) horizontal forces, and (b) vertical forces.

\subsection{Duration of Force Events}

As mentioned in Section 3.2, 59 values (29 for Crest wall A +30 for Crest wall B) and 47 (22 for Crest wall $\mathrm{A}+25$ for Crest wall B) of the duration corresponding to the force exceeded by $0.1 \%$ of incoming waves $\left(\right.$ duration $_{0.1 \%}$ ) were obtained for the horizontal $\left(\right.$ duration $_{H, 0.1 \%}$ ) and vertical (duration ${ }_{V, 0.1 \%}$ ) forces, respectively. duration ${ }_{H, 0.1 \%}$ and duration $_{V, 0.1 \%}$ corresponding to the same test were compared in order to determine if they present the same behavior. Note that 47 duration $_{0.1 \%}$ values could be compared (i.e., the minimum number of duration ${ }_{0.1 \%}$ values, which corresponds to the vertical forces). Figure 11 compares duration ${ }_{H, 0.1 \%}$ and duration $n_{V, 0.1 \%}$ corresponding to the same test.

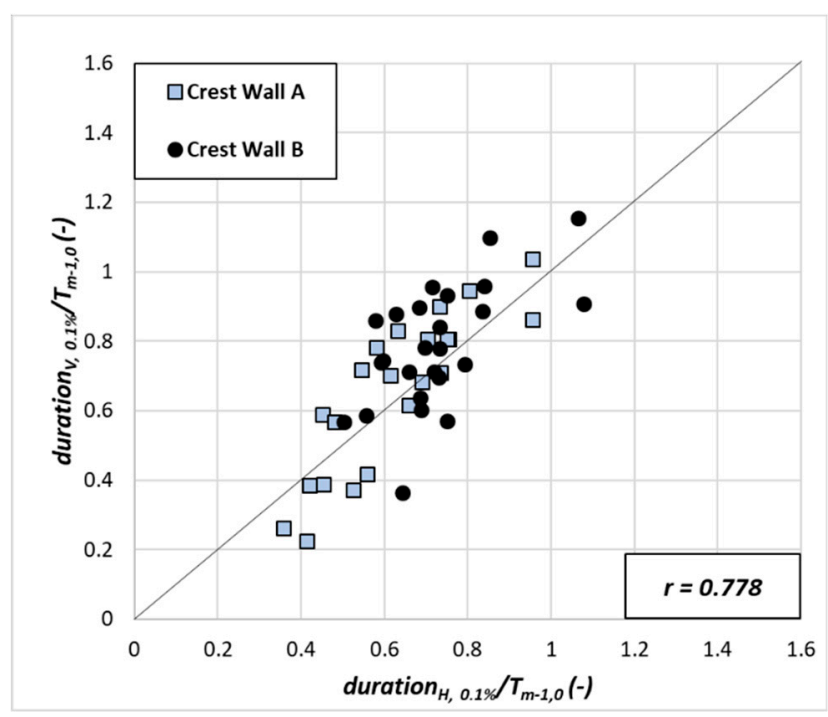

Figure 11. Comparison between the measured dimensionless duration $0.1 \%$ (duration $\left.0.1 \% / T_{m-1,0}\right)$ for horizontal and vertical forces. 
Reasonable correlation was observed $(r=0.778)$ between duration $_{H, 0.1 \%}$ and duration $n_{V, 0.1 \%}$. Thus, it is reasonable to analyze them together. Equation (7) was proposed to estimate duration $0.1 \%$, based on the difference between $R u_{2 \%}$ and $A_{C}$.

$$
\text { duration }_{0.1 \%}=5 \sqrt{H_{\text {wall }} \frac{\gamma_{\beta}\left(R u_{2 \%}-A_{C}\right)}{H_{S}}}
$$

Note that if $A_{C} \geq R u_{2} \%$, no waves reach the crest, which leads to duration $0.1 \%=0$. Equation (7) also shows that the duration of the force event increases for the larger crest walls $\left(H_{\text {wall }}\right)$; larger crest walls are a bigger obstacle to dissipating phenomena (infiltration and wave overtopping), such that the water remains longer at the breakwater crest. Equation (7) is valid within the ranges $0.260 \leq \gamma_{\beta}\left(R u_{2 \%}\right.$ $\left.-A_{C}\right) / H_{S} \leq 0.863$. In order to assess the goodness of fit, $r$ and the relative mean squared error $(r M S E)$ were used.

$$
r M S E=\frac{M S E}{v a r}=\frac{\frac{1}{N_{o}} \sum_{i=1}^{N_{o}}\left(t_{i}-e_{i}\right)^{2}}{\frac{1}{N_{o}} \sum_{i=1}^{N_{o}}\left(t_{i}-\bar{t}\right)^{2}}
$$

where MSE is the mean squared error, var is the variance of the target values, $N_{o}$ is the number of observations, $t_{i}$ and $e_{i}$ are the target and estimated values, respectively, and $\bar{t}$ is the average of the target values. The variation coefficient $(C V)$ of the data was also calculated as $C V=\sigma / \mu$, where $\sigma$ is the standard deviation of the observations and $\mu$ is the observations' mean.

Figure 12 compares the measured and estimated dimensionless duration (duration $0.1 \% / T_{m-1,0}$ ) using Equation (7), as well as the 90\% confidence interval. Here, $r=0.726$ and $r M S E=0.472$.

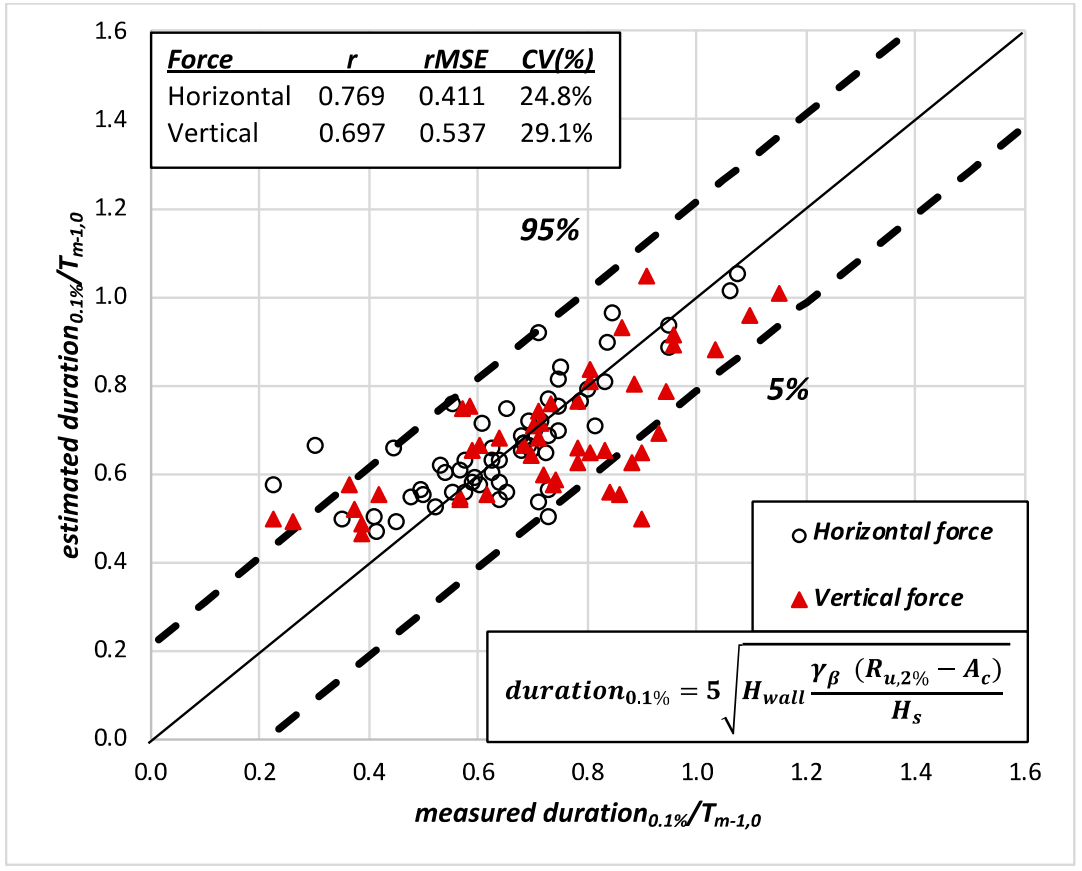

Figure 12. Comparison between the measured and estimated dimensionless duration $0.1 \%$ using Equation (7).

The MSE remained stable with increasing values of duration $0.1 \% / T_{m-1,0}$. Thus, the $90 \%$ confidence interval was calculated based on the variance of the error $(\operatorname{var}(\varepsilon)=0.0167)$. Assuming a Gaussian error distribution, the confidence interval is obtained as

$$
\left.\frac{\text { duration }_{0.1 \%}}{T_{m-1,0}}\right|_{5 \%} ^{95 \%}=\frac{\text { duration }_{0.1 \%}}{T_{m-1,0}} \pm 1.64 \sqrt{\operatorname{var}(\varepsilon)}=\frac{\text { duration }_{0.1 \%}}{T_{m-1,0}} \pm 0.212
$$


Similar to Section 4.1, the correlation between the Extracted register and a new triangle-shaped register was assessed. Here, the triangle-shaped register was created using the estimated $F_{H, 0.1 \% \text {, }}$ $F_{V, 0.1 \%}$, and duration $0.1 \%$ using the method in [5] (Equations (1) to (4)) and Equation (7). tpeak $0.1 \%$ in Equation (6) was again calibrated by maximizing the correlation; $K_{\text {peak }}=0.15$ and $K_{\text {peak }}=0.35$ were obtained for horizontal and vertical forces, respectively; $0.874 \leq r \leq 0.879$. Figure 13 shows the superposition of the Extracted register (the actual maximum force events) and the triangle-shaped model generated with the estimated $F_{H, 0.1 \%}, F_{V, 0.1 \%}$, and duration $0.1 \%$. Note that if $\left(R u_{2 \%}-A_{C}\right) \leq 0$ or $\left(R u_{2} \%-0.75 A_{C}\right) \leq 0, F_{H, 0.1 \%}$ or $F_{V, 0.1 \%}$ result in 0 , respectively.
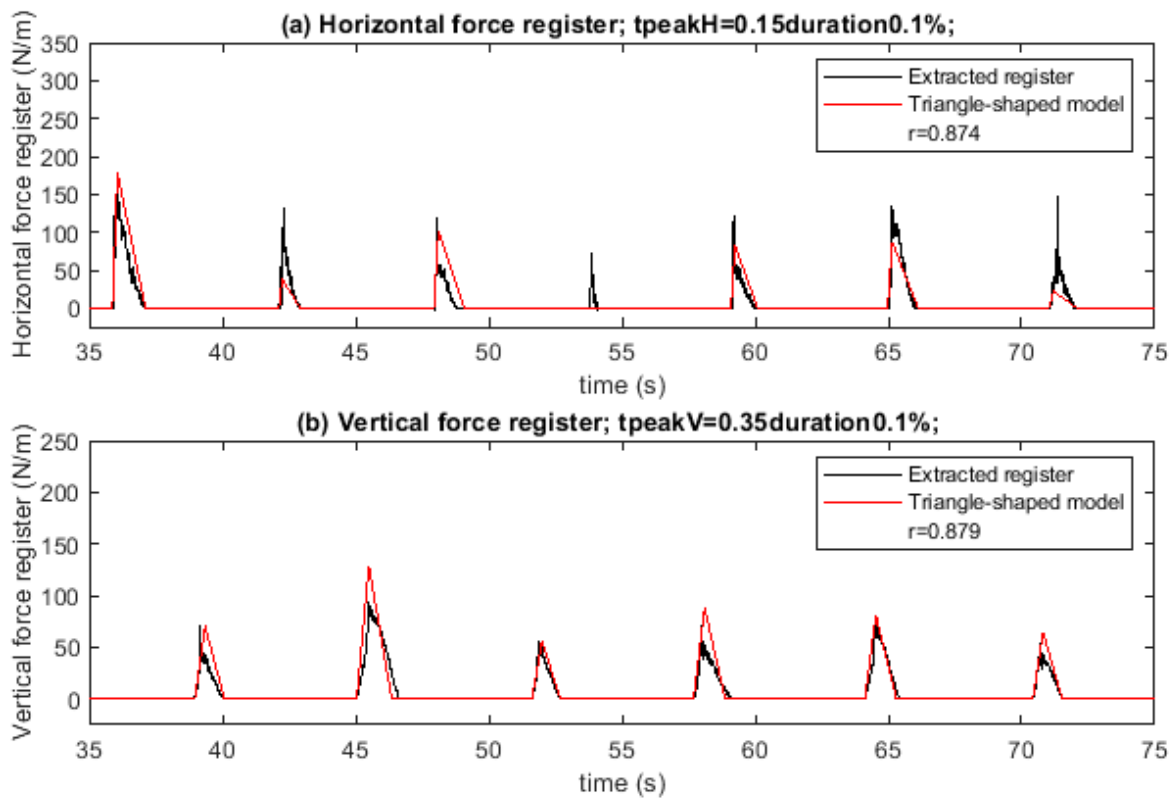

Figure 13. Comparison of Extracted register (the actual maximum force events) and the triangle-shaped model using the estimated $F_{H, 0.1 \%}, F_{V, 0.1 \%}$, and duration $0.1 \%$ for (a) horizontal forces and (b) vertical forces.

\subsection{Travel Time and Velocity of Force Events}

As discussed in Section 4.1, a triangle-shaped model is adopted for the time evolution of both horizontal and vertical force events. Since the area of a triangle depends on the base (duration $0.1 \%$ ) and the height (maximum loading), the method proposed in [5] (Equations (1) to (4)) and Equation (7) can be used to estimate the area of the actual force in the time domain. In order to transform the temporal shape into the space domain, the velocity $\left(v_{F}\right)$ at which the force event travels is needed. To assess $v_{F}$, the travel time of the force events between the two measurement points was obtained. $v_{F}$ was calculated dividing the distance between the measurement points $(6.7 \mathrm{~m})$ between the travel time.

In order to extract the travel time from the experimental registers, the register measured at point $\mathrm{B}$ (see Figure 1) was moved forward in steps of $0.01 \mathrm{~s}$ from $0 \mathrm{~s}$ (no displacement) to $5 \mathrm{~s}$. For each step, the correlation between Register A and the displaced Register B was calculated. The travel time corresponded to the displacement time, which maximizes the correlation. This procedure could not be applied to three out of the 30 analyzed vertical force registers, since they were too low. Thus, 57 travel time values (30 values for horizontal forces and 27 for vertical forces) were obtained. Figure 14 shows an example of the exposed procedure for the horizontal force registers in Test \#5, whereas Figure 15 presents a comparison between Register A and the original and displaced Register B until the travel time, which maximizes the correlation for Test \#5. 


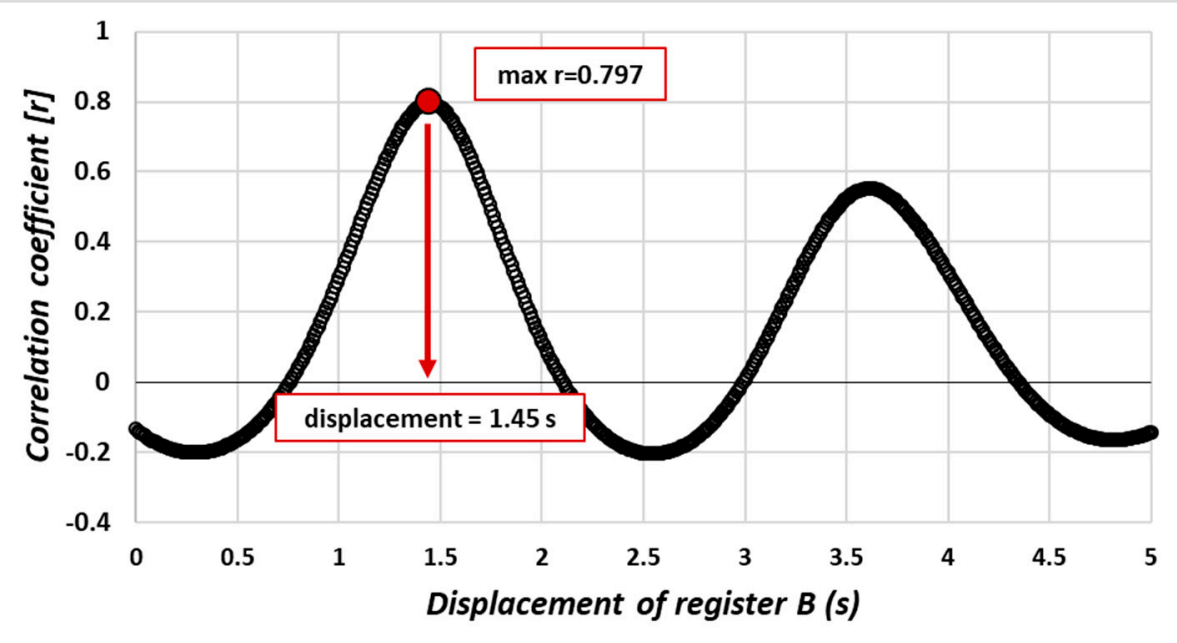

Figure 14. Example of the procedure to determine the travel time between the two measurement points (Test \#5).
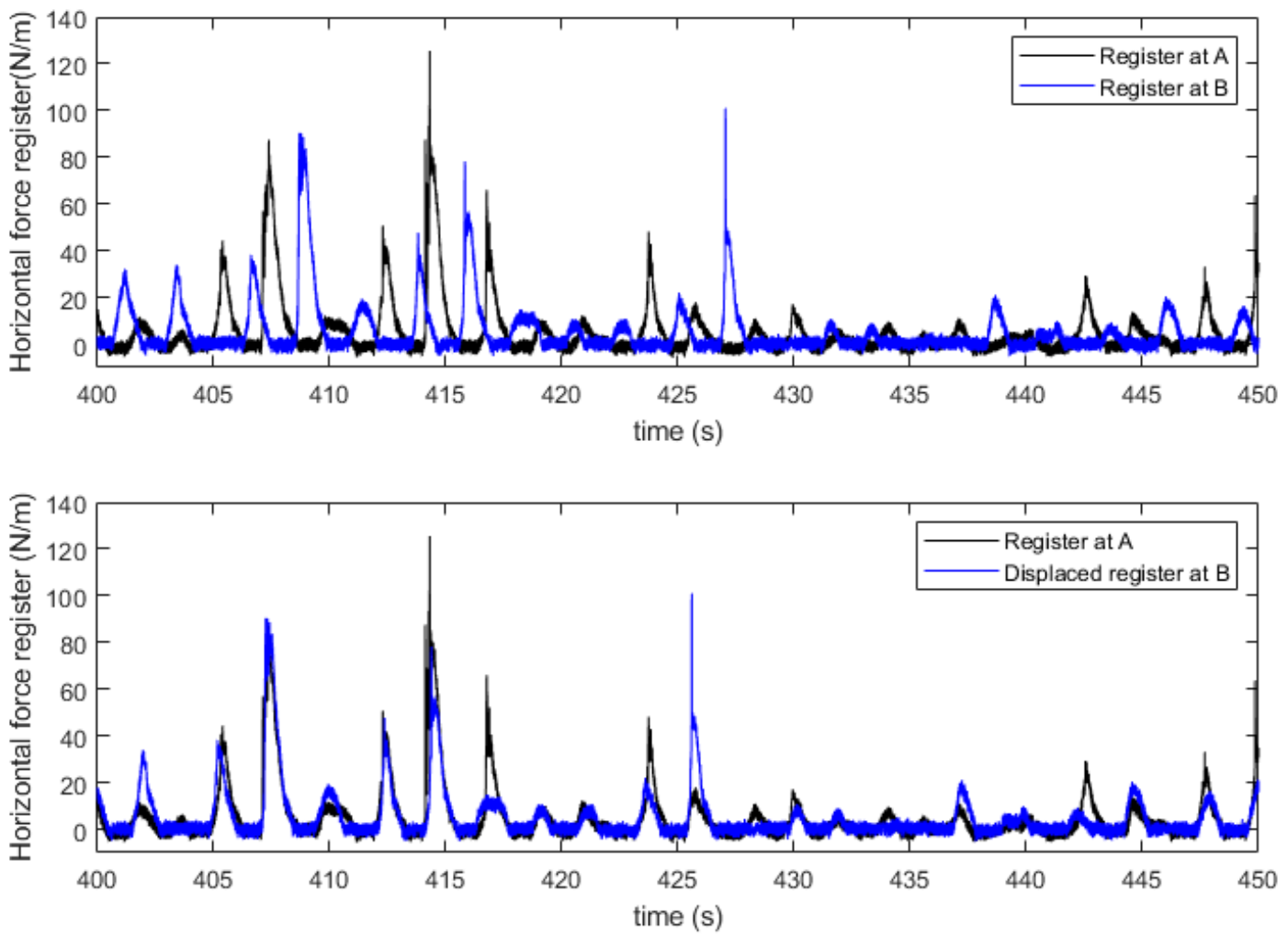

Figure 15. Example of applying the maximum correlation travel time to displace the register at measurement point B (Test \#5).

Once the travel time was determined for both the horizontal and vertical forces, the travel time values corresponding to the same test were compared to determine whether the behavior was equal for both types of forces (see Figure 16). In total, 27 pairs of values could be compared (minimum number of travel time values, which corresponds to those available from measured vertical forces). 


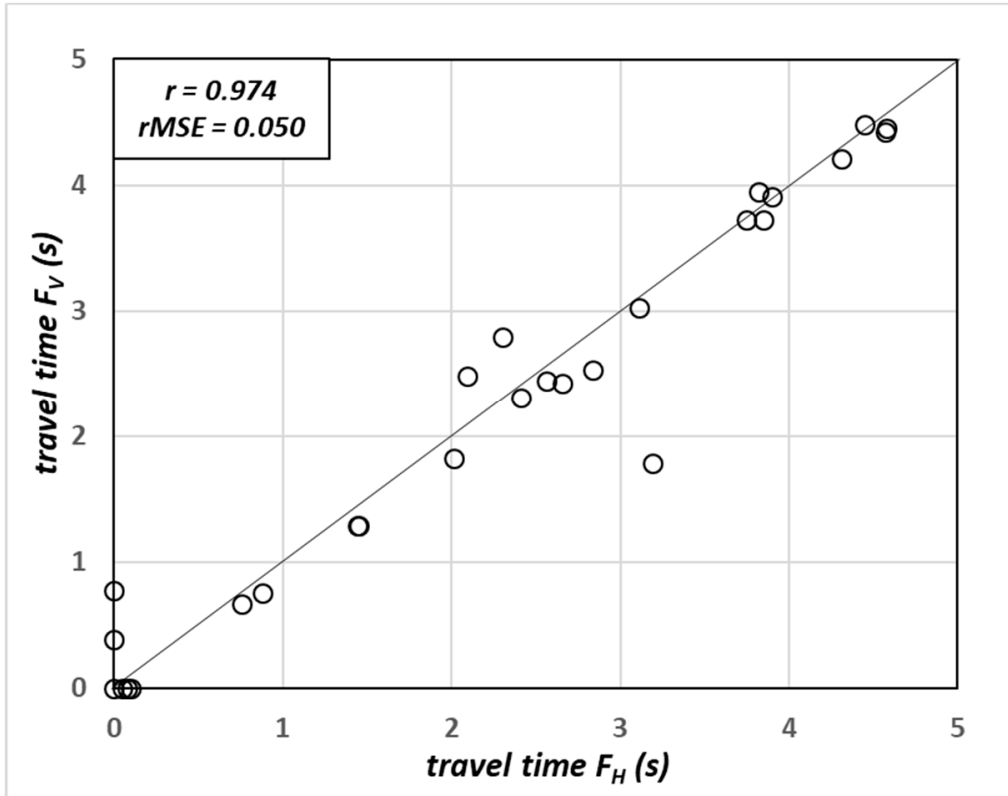

Figure 16. Comparison between the travel time of horizontal and vertical force events corresponding to the same test.

As shown in Figure 16, a very good agreement between the travel time of both horizontal and vertical force events corresponding to the same test was found $(r=0.974 ; r M S E=0.050)$. Therefore, it is reasonable to analyze the travel time for horizontal and vertical forces together.

$v_{F}$ was determined by dividing the distance between the two measurement points $(6.7 \mathrm{~m})$ between the obtained travel time. The higher the angle, the lower the observed velocity. Note that the travel time for tests with perpendicular waves was zero, since the crest wall is impacted by the whole wave front at the same time. Thus, the tests with perpendicular wave attack could not be used to analyze $v_{F}$; $45 v_{F}$ values were obtained.

A very high correlation was observed between the dimensionless velocity of the maximum force along the structure $\left(v_{F} /\left(g h_{s}\right)^{0.5}\right.$, where $h_{S}$ is the water depth at the toe of the structure) and $\sin \beta(r=$ 0.826). Therefore, Equation (10) was proposed for $v_{F} /\left(g h_{s}\right)^{0.5}$

$$
\frac{v_{F}}{\left(g h_{s}\right)^{0.5}}=\frac{0.2}{\sin ^{1.2} \beta s_{m-1,0} 0.3}
$$

Equation (10) is valid for $15^{\circ} \leq \beta \leq 75^{\circ}$ and $0.018 \leq s_{m-1,0} \leq 0.048$. Figure 17 presents the comparison between the measured and estimated dimensionless velocity $v_{F} /\left(g h_{s}\right)^{0.5}$ with Equation (10), as well as the $90 \%$ confidence interval. Here, $93.4 \%$ of the variance was explained by the model.

The $90 \%$ confidence interval is calculated following the methodology given in [16]. As the MSE increases with increasing $v_{F} /\left(g h_{s}\right)^{0.5}$, the variance of the error $(\operatorname{var}(\varepsilon))$ is calculated as

$$
\operatorname{var}(\varepsilon)=0.035\left[\frac{v_{F}}{\left(g h_{s}\right)^{0.5}}\right]
$$

Assuming a Gaussian error distribution, the $90 \%$ confidence interval for $v_{F} /\left(g h_{s}\right)^{0.5}$ estimated using Equation (10) is given in Equation (12).

$$
\left.\frac{v_{F}}{\left(g h_{s}\right)^{0.5}}\right|_{5 \%} ^{95 \%}=\frac{v_{F}}{\left(g h_{s}\right)^{0.5}} \pm 0.31 \sqrt{\frac{v_{F}}{\left(g h_{s}\right)^{0.5}}}
$$




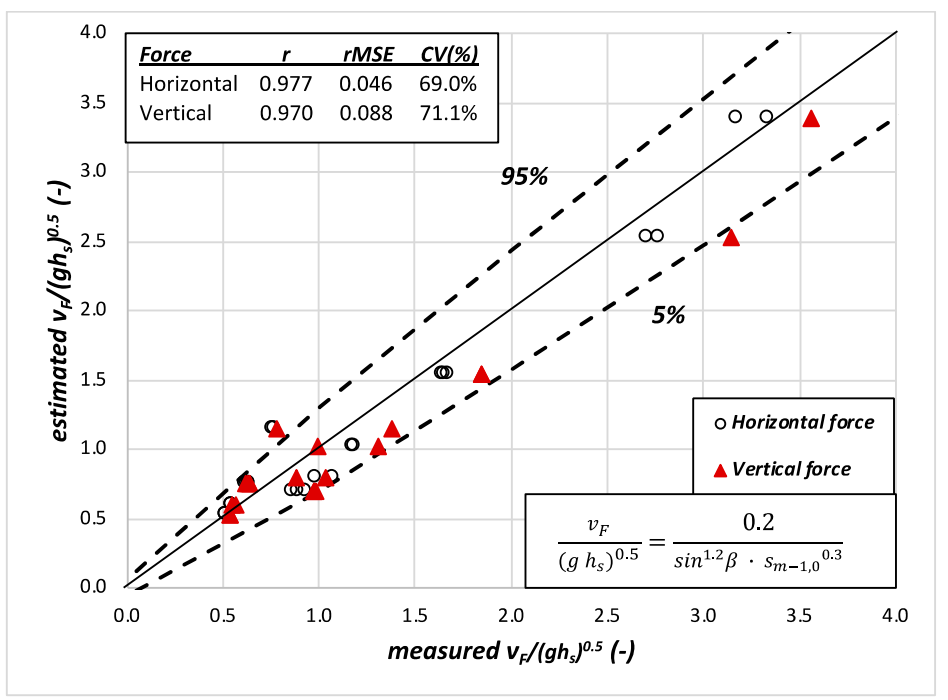

Figure 17. Comparison between the measured and estimated $v_{F} /\left(g h_{S}\right)^{0.5}$ using Equation (10).

\subsection{Integration of the Actual Force}

The triangle-shaped force diagram along the longitudinal dimension of the crest wall was obtained for both the horizontal and vertical force events using the method proposed in [5] to calculate the maximum loading (Equations (1) to (4)) and Equations (7) and (10) to estimate duration $0.1 \%$ and $v_{F}$. The actual force $\left(A F_{0.1 \%}\right)$ that attacks the structure can be calculated using the formula for the triangle area,

$$
A F_{0.1 \%}=0.5\left(\text { duration }_{0.1 \%} v_{F}\right) F_{0.1 \%}
$$

where $F_{0.1 \%}$ is the maximum estimated loading for the horizontal or vertical force with [5]. Equation (13) is valid while the length of the crest wall $\left(L_{\text {crest }}\right)$ is higher than the width of the force event duration $_{0.1 \%}$ $v_{f}$ ). If duration $_{0.1 \%} v_{f}>L_{\text {crest }}$, the considered portion of the area within the triangle needs to be the maximum possible value to obtain the dominant force (see the right panel of Figure 18). For every case, 20 values of $L_{\text {crest }}$ were considered. $L_{\text {crest }}=K_{A}$ duration $_{0.1 \%} v_{f}$, where $K_{A}$ was varied from 0.05 to 1 in steps of 0.05 . The maximum area within the triangle was numerically integrated for every case and $L_{\text {crest }}$. Similar to the estimated $A F_{0.1 \%}$, the measured $A F_{0.1 \%}$ was obtained as the maximum numerically integrated area from the force register in the space domain. For the numerical integration, the following steps were performed: (1) a vector with the same length as the time register is created, and all its values are set equal to the time step (0.001 $\mathrm{s}$ in this study), (2) the vector is multiplied by the measured velocity, (3) the cumulative sum is determined, and (4) the force register is numerically integrated over this new space vector. Figure 19 shows the comparison between the measured and estimated $A F_{0.1 \%}$ using the method in [5] (Equations (1) to (4)) and Equations (7) and (10). Here, $r=0.938$ and $r M S E=0.945$.

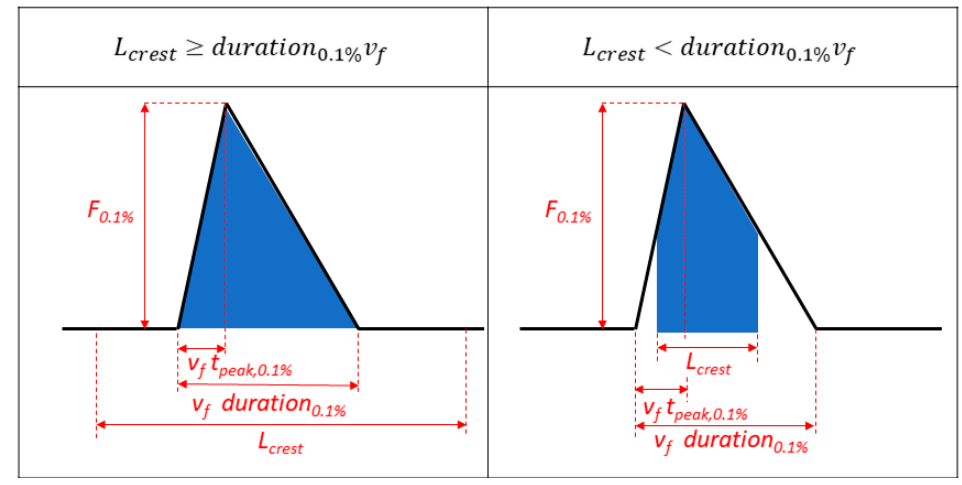

Figure 18. Possible situations when calculating $A F_{0.1 \%}$. 


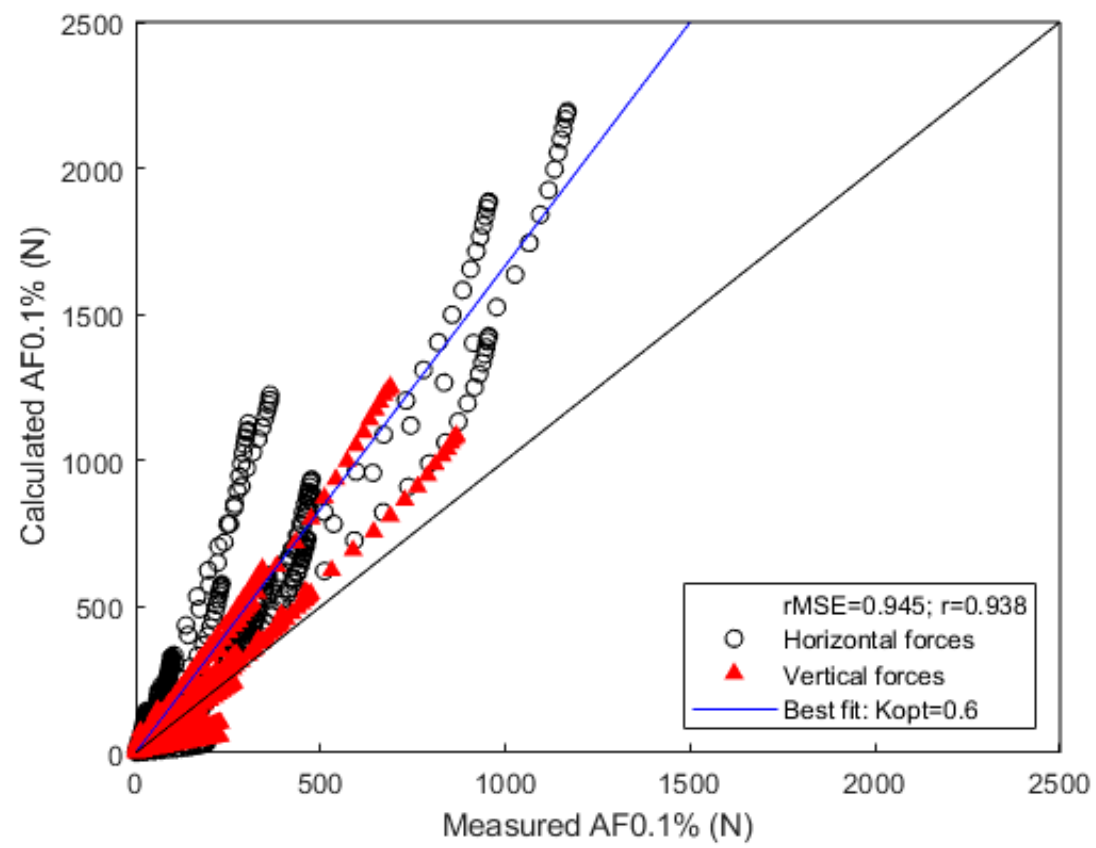

Figure 19. Comparison between the measured and estimated $A F_{0.1 \%}$ using Equations (1)-(4), (7), and (10).

Every alignment of points in Figure 19 represents the $A F_{0.1 \%}$ variation for one test due to the different values of $K_{A}$. As shown in Figure 19, the proposed method is on the conservative side. In order to obtain the best fitting approach, $A F_{0.1 \%}{ }^{*}=K_{\text {opt }} A F_{0.1 \%}$ is considered where $A F_{0.1 \%}{ }^{*}$ is the best fit estimated $A F_{0.1 \%}$ and $K_{\text {opt }}$ is a coefficient to be calibrated. $K_{\text {opt }}$ was calibrated by minimizing the $r M S E$. The best fit was obtained for $K_{\text {opt }}=0.6$ with $r M S E=0.133$. Figure 20 presents the comparison between the measured $A F_{0.1 \%}$ and estimated $A F_{0.1 \%}$ * using the method in [5] (Equations (1)-(4)) and Equations (7) and (10) with $K_{\text {opt }}=0.6$, as well as the $90 \%$ confidence interval.

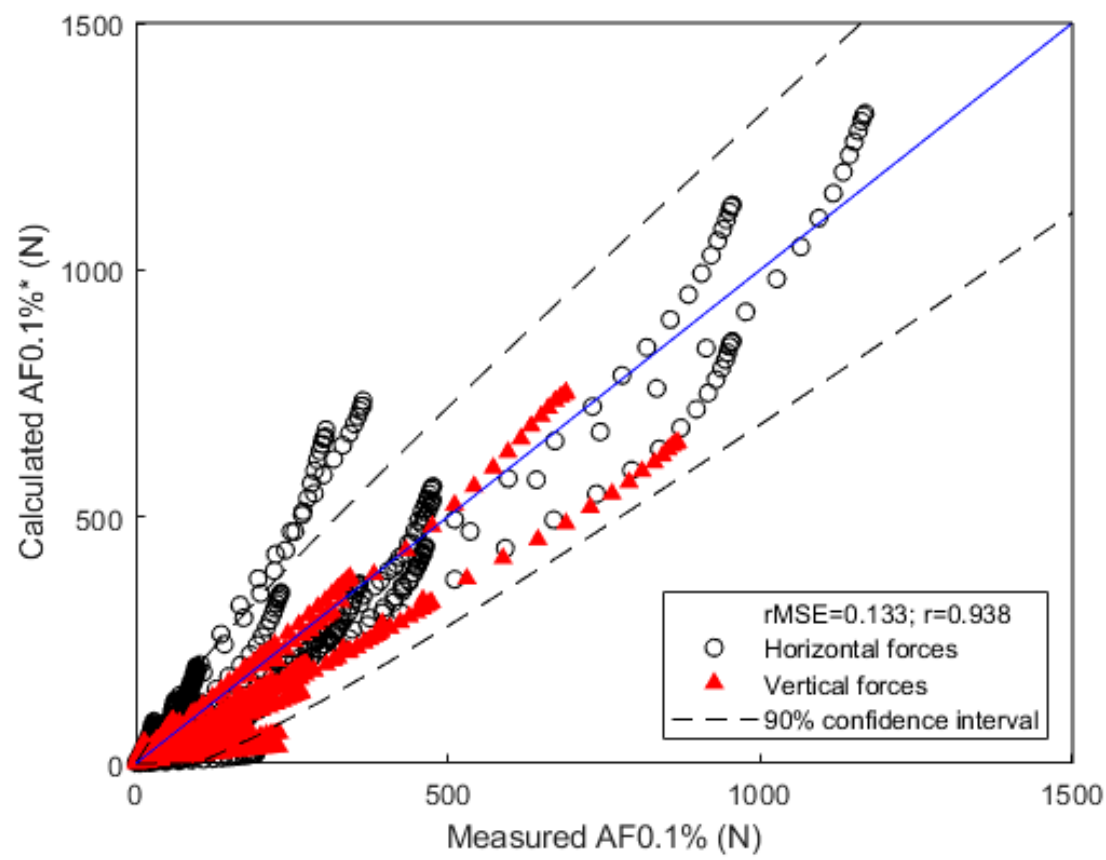

Figure 20. Comparison between the measured $A F_{0.1 \%}$ and estimated $A F_{0.1 \%}{ }^{*}$ using Equations (1)-(4), (7), and (10) with $K_{\text {opt }}=0.6$, as well as the $90 \%$ confidence interval. 
Similar to Section 4.3 , since the MSE increases with increasing $A F_{0.1 \%}{ }^{*}, \operatorname{var}(\varepsilon)$ is calculated as

$$
\operatorname{var}(\varepsilon)=36.5 A F_{0.1 \%}{ }^{*}
$$

Assuming a Gaussian error distribution, the $90 \%$ confidence interval for $A F_{0.1 \%}{ }^{*}$ is given in Equation (15).

$$
A F_{0.1 \%}{ }^{*}{ }_{5 \%}^{95 \%}=A F_{0.1 \%}{ }^{*} \pm 9.91 \sqrt{A F_{0.1 \%}{ }^{*}}
$$

\subsection{Length Coefficient}

The goal of this study was to propose a reduction coefficient to directly multiply to the force obtained with the methods in the literature to account for the effect of the finite length of crest walls under oblique wave attack. Methods in the literature provide the maximum force that attacks a chainage of the crest wall $\left(F_{0.1 \%}\right)$. They assume that the whole crest wall is attacked by this maximum force; a rectangle-shaped diagram along the whole crest wall length is assumed, as illustrated in the left panel of Figure 21. Thus, the total force $A F_{0.1 \%}$ on a crest wall section is generally estimated by multiplying $F_{0.1 \%}$ by the length of the crest wall $\left(L_{\text {crest }}\right)$. Figure 21 illustrates the horizontal force diagrams along the crest wall as generally applied compared to the method proposed in the present study. As previously mentioned, vertical force diagrams were defined in the same way. The length coefficient $\left(\gamma_{L}\right)$ was calculated by dividing $A F_{0.1 \%}$ estimated using the results of the present study ("triangular shape") with the best fitting approach by the $A F_{0.1 \%}$ without the finite length effect ("rectangular shape"). Equation (16) is derived

$$
\gamma_{L}=\frac{0.6 \cdot 0.5\left(\text { duration }_{0.1 \%} v_{F}\right) F_{0.1 \%}}{L_{\text {crest }} F_{0.1 \%}}=0.24 \frac{\sqrt{H_{\text {wall }} \gamma_{\beta}\left(R u_{2 \%}-A_{c}\right)}}{L_{\text {crest }} H_{s}{ }^{0.5} \sin ^{1.2} \beta s_{m-1,0} 0.3}
$$

where Equation (3) is used for $R u_{2} \%$ and Equation (4) is used for $\gamma_{\beta}$. Thus, Equation (16) is only valid if $L_{\text {crest }} \geq\left(\right.$ duration $\left._{0.1 \%} v_{F}\right)$.

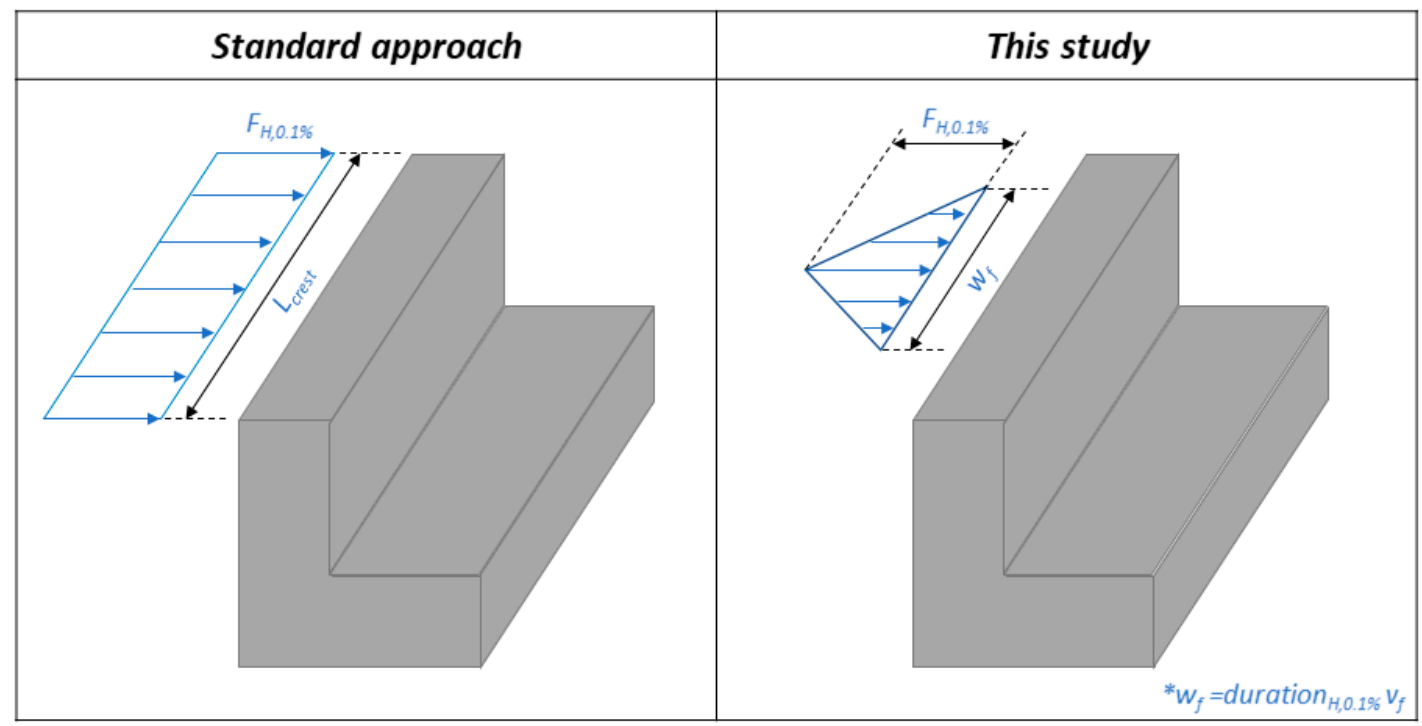

Figure 21. Example of the horizontal force diagram along the longitudinal dimension of the crest wall assumed by the standard method (left panel) and the present study (right panel).

As mentioned in Section 4.4, when duration $_{0.1 \%} v_{f}>L_{\text {crest }}$, the considered portion of the area within the triangle needs to be the maximum (see Figure 18). Since the area calculation is not direct, a new equation is derived. Cases within the tested experimental ranges were generated. $s_{m-1,0}=0.02$ and $0.04, \beta=15^{\circ}, 30^{\circ}, 45^{\circ}, 60^{\circ}$, and $75^{\circ}, h_{s}=0.77 \mathrm{~m}, A_{C}=0.12 \mathrm{~m}$ and $H_{w a l l}=0.15$ and $0.20 \mathrm{~m}$ were 
considered. Values for $H_{s}$ were selected such that the generated cases remain within the experimental range of tested values for $R u_{2} \% / A_{C}$. Test conditions were used for cross-validation. Both the generated cases and the test conditions cases were applied to five lengths of the crest wall $\left(L_{\text {crest }}=2.25 \mathrm{~m}, 5 \mathrm{~m}\right.$, $10 \mathrm{~m}, 15 \mathrm{~m}$, and $20 \mathrm{~m}$ on the scale of the model). Thus, 187 generated cases and 235 test conditions were used to illustrate the obtained method. The considered values of $L_{\text {crest }}$ went from approximately the smallest $L_{m-1,0}$ until $2 L_{m-1,0}$ of the highest $L_{m-1,0}$.

$F_{H, 0.1 \%}$ and $F_{V, 0.1 \%}$ were calculated using the methodology given in [5] (Equations (1) to (4)). Note that $K_{e, v}$ needed to be interpolated for the generated cases $\left(K_{e, v}=2.35\right.$ and 1.81 for $s_{m-1,0}=0.02$ and 0.04 , respectively). $A F_{0.1 \%}$ using the results of this study were obtained with the best fitting option $\left(K_{\text {opt }}=0.6\right)$ with Equations (7) and (10). The reduction factor $\gamma_{L}$ is calculated by dividing $A F_{0.1 \%}$ obtained with the results from this study ("triangular shape") by the $A F_{0.1 \%}$ calculated with the generally applied method ("rectangular shape" with the maximum force acting on the entire crest wall at the same instant).

The same trend was observed in $\gamma_{L}$ for both horizontal and vertical force events. Equation (17) was proposed based on the generated cases. Thus, for relatively short crest walls with $L_{\text {crest }}<\left(\right.$ duration $_{0.1 \%}$ $\left.v_{F}\right)$, the following expression is proposed:

$$
\gamma_{L}=6.5\left[\frac{A_{C}}{H_{S}}\right]^{2}\left[\frac{\left(\gamma_{\beta} R u_{2} \%-A_{C}\right)}{L_{\text {crest }}}\right]^{0.65}
$$

where Equation (3) is used for $R u_{2} \%$ and Equation (4) is used for $\gamma_{\beta}$, which accounts for the effect of oblique wave attack. The reduction factor expressed by Equations (16) and (17) are valid within the ranges $0.541 \leq A_{C} / H s \leq 1.102 ; 0 \leq\left(\gamma_{\beta} R u_{2 \%}-A_{C}\right) / L_{\text {crest }} \leq 0.045$. Since Equations (16) and (17) do not depend on $F_{0.1 \%}$, they are applicable independently on the method used to estimate $F_{0.1 \%}$. Note that the higher the wave attack angle, the lower $\gamma_{L}$ and the higher the reduction on the crest wall forces. Figure 22 compares the goal $\gamma_{L}$ and the estimated $\gamma_{L}$ using Equation (17) for (a) horizontal forces and (b) vertical forces, as well as the $90 \%$ confidence interval. Open symbols correspond to the generated cases, while closed symbols correspond to the test conditions cases used as cross-validation.
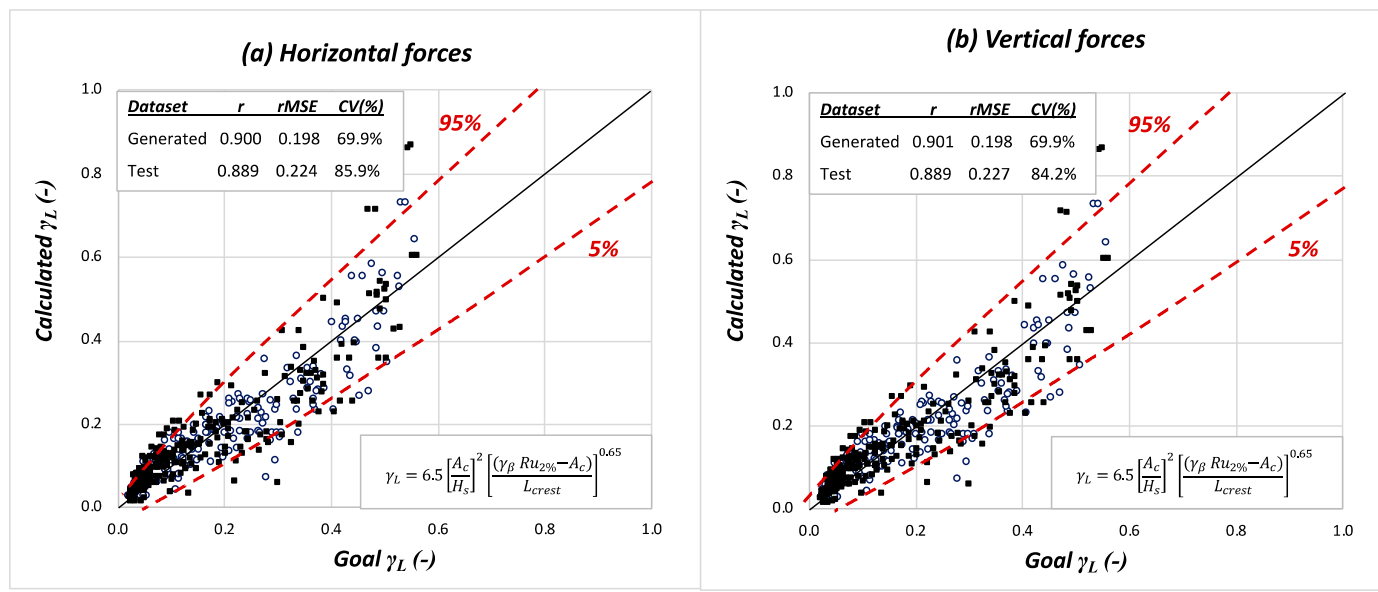

Figure 22. Comparison between the goal $\gamma_{L}$ and the estimated $\gamma_{L}$ with Equation (16), as well as the $90 \%$ confidence interval for (a) horizontal forces and (b) vertical forces. Generated cases correspond to open symbols, while test conditions correspond to closed symbols.

Similar to Sections 4.3 and $4.4, \operatorname{var}(\varepsilon)$ is calculated as:

$$
\operatorname{var}(\varepsilon)=0.019 \gamma_{L}
$$


Assuming a Gaussian error distribution, the $90 \%$ confidence interval for $\gamma_{L}$ is given by:

$$
\left.\gamma_{L}\right|_{5 \%} ^{95 \%}=\gamma_{L} \pm 0.23 \sqrt{\gamma_{L}}
$$

Note that the confidence interval was calculated for the generated cases. The agreement is rather good for both the generated cases and the test conditions $(0.198 \leq r M S E \leq 0.227)$.

\section{Conclusions}

To estimate the forces on a crest wall of a rubble mound structure, the predicted maximum force at a single position (chainage) is normally assumed to act on the entire length of the crest wall. For perpendicular wave attack, this is a reasonable approach. However, for oblique wave attack, the maximum loading is not acting on the entire length of the crest wall at the same instant. Since crest walls have a finite length, assuming that the maximum wave loading acts at the same instant over the entire length of the crest wall leads to an overestimation of the actual forces on crest walls under oblique wave attack. This study describes a method to account for the effect of the finite length of crest walls on the forces caused by oblique wave attack.

The physical model tests conducted by [5] in a wave basin were used. A triangular shape is applied to model the temporal shape of the (horizontal and vertical) force events (exceeded by $0.1 \%$ of the incoming waves) with $0.912 \leq r \leq 0.924$. It was found that the duration of the force events (duration $_{0.1 \%}$ ) (base of the triangle) is the same for both horizontal and vertical forces. Equation (7) is proposed to estimate the duration of the force events $(r M S E=0.472)$. Equation $(6)$ is derived to estimate the position of the peak within the force event; the rising time of the horizontal forces is faster than for the vertical forces. The method proposed in [5] was suggested to calculate the maximum loading $\left(F_{0.1 \%}\right)$. The agreement between the calculated and measured force register was good $(0.874 \leq r \leq 0.879)$.

The temporal shape of the force events was transformed into the space domain by means of the velocity at which the force event travels along the structure $\left(v_{f}\right)$. To this end, the travel time between two measurement points was determined, and $v_{f}$ was obtained by dividing the distance between both points between the travel time. The same travel time and $v_{f}$ were obtained for horizontal and vertical forces. The travel time obviously is 0 for perpendicular wave attack, since the whole crest wall is impacted by the wave in the same instant. Equation (10) was proposed to calculate $v_{f}$ for oblique wave attack with a rather high accuracy $(r M S E=0.066)$.

The actual force on the entire crest wall with a finite length $\left(A F_{0.1 \%}\right)$ was obtained using a triangular shape in the space domain. The adopted approach resulted in conservative estimates of the reduction due to the finite length of crest walls under oblique wave attack. The best fit for actual force on the entire crest wall with a finite length $\left(A F_{0.1 \%}\right)$ resulted in $60 \%$ of the triangular shape $\left(K_{\text {opt }}=0.6\right)$ with $r M S E=0.133$.

A new reduction factor $\left(\gamma_{L}\right)$ was defined as the ratio between $A F_{0.1 \%}$ estimated using the findings of the present study and the maximum force acting against the crest wall $\left(F_{0.1 \%} L_{\text {crest }}\right)$. Equations (16) and (16) were proposed to directly estimate $\gamma_{L}$ for both horizontal and vertical forces. Equation (16) is valid if $L_{\text {crest }} \geq\left(\right.$ duration $\left._{0.1 \%} v_{F}\right)$. Equation (17) was developed to account for relatively short crest walls $L_{\text {crest }}<\left(\right.$ duration $\left._{0.1 \%} v_{F}\right)$. To obtain Equation (17), the methodology developed in this study using the best fit approach $\left(K_{\text {opt }}=0.6\right)$ was applied on two data sets: $(1)$ generated cases within the experimental ranges with five values of the length of the crest wall $\left(L_{c r e s t}\right)$ and (2) tests conditions with five values of $L_{\text {crest }}$. The forces on the entire crest wall with finite length $\left(A F_{0.1 \%}\right)$ were also calculated using the generally applied method $\left(A F_{0.1 \%}=F_{0.1 \%} L_{\text {crest }}\right)$. Equation (17) was derived using dataset (1), while dataset (2) was used for cross-validation $(0.198 \leq r M S E \leq 0.227)$. Since the derived reduction factor, expressed by Equations (16) and (17), does not depend on $F_{0.1 \%}$, Equations (16) and (17) are applicable independently on the estimator used for $F_{0.1 \%}$.

The expressions proposed in this study are valid within the ranges of the present tests $(0.84 \leq$ $\left.R_{c} / H_{s} \leq 1.6 ; 1.27 \leq R_{c} / A_{c} \leq 1.55 ; 0 \leq F_{b} / H_{s} \leq 0.56 ; 0.13 \leq H_{s} / h_{s} \leq 0.27\right)$. It is encouraged to check their 
validity out of the experimental ranges of this study, paying special attention to the effect of wave characteristics on the shape of the force events, different crest wall geometries, and armor layers (1:2 rock armored slopes).

This study has illustrated how large the reduction in the required size of the crest wall can be if the finite length of the crest wall is taken into account in oblique wave attack conditions. Therefore, it is recommended to take into account not only the reduction in the maximum forces due to oblique waves, but also the reduction due to the fact that the maximum forces do not occur at the same instant over the entire length of crest walls on rubble mound breakwaters.

Author Contributions: P.M.-N. performed the data analysis, was responsible for the model conceptualization, and drafted the original manuscript. M.R.A.v.G. conceived the research topic, designed the research plan, supervised the investigation, and reviewed and approved the manuscript. All authors have read and agreed to the published version of the manuscript.

Funding: The first author was financially supported by the Ministerio de Educación, Ciencia y Deporte through the FPU program (Formación de Profesorado Universitario) under grant FPU16/05081.

Acknowledgments: The first author was financially supported by the Ministerio de Educación, Ciencia y Deporte through the FPU program (Formación de Profesorado Universitario) under grant FPU16/05081.

Conflicts of Interest: The authors declare no conflict of interest. The funders had no role in the design of the study; in the collection, analyses, or interpretation of data; in the writing of the manuscript, or in the decision to publish the results.

\section{References}

1. Pedersen, J. Wave Forces and Overtopping on Crown Walls of Rubble Mound Breakwaters-An Experimental Study. Ph.D. Thesis, Aalborg University, Aalborg, Denmark, 1996.

2. Molines, J.; Herrera, M.P.; Medina, J.R. Estimations of wave forces on crown walls based on wave overtopping rates. Coast. Eng. 2018, 132, 50-62. [CrossRef]

3. Van Gent, M.R.A.; Van der Werf, I.M. Prediction method for wave overtopping and wave forces on rubble mound breakwater crest walls. In Proceedings of the Coastal Structures, Hannover, Germany, 30 September-2 October 2019.

4. Jacobsen, N.G.; Van Gent, M.R.A.; Capel, A.; Borsboom, M. Numerical prediction of integrated wave loads on crest walls on top of rubble mound breakwaters. Coast. Eng. 2018, 142, 110-124. [CrossRef]

5. Van Gent, M.R.; Van Der Werf, I.M. Influence of oblique wave attack on wave overtopping and forces on rubble mound breakwater crest walls. Coast. Eng. 2019, 151, 78-96. [CrossRef]

6. Jensen, O.J. A Monograph of Rubble Mound Breakwaters. Available online: https://repository.tudelft.nl/ islandora/object/uuid\%3A133be463-5f43-45cd-9115-3ef9ebe245b3 (accessed on 26 January 2020).

7. Günbak, A.R.; Gökce, T. Wave screen stability of rubble mound Breakwaters. In Proceedings of the International Symposium of Maritime Structure in the Mediterranean Sea, Athens, Greece, 1984.

8. Brunn, P. Damage of Tripoli harbor north west breakwater. In Design and Construction of Mounds for Breakwaters and Coastal Protection; Brunn, P., Ed.; Elsevier: Amsterdam, The Netherlands, 1985; pp. 676-695.

9. Martin, F.L. Experimental Study of Wave Force on Rubble Mound Breakwater Crown Walls; PIANC Bulletin: Brussels, Belgium, 1999.

10. Martin, F.L.; Losada, M.Á.; Medina, R. Wave loads on rubble mound breakwater crown walls. Coast. Eng. 1999, 37, 149-174. [CrossRef]

11. Molines, J. Wave overtopping on Crown Wall Stability of Cube and Cubipod armored Mound Breakwaters. Ph.D. Thesis, Universitat Politècncia de València, Valencia, Spain, 2016.

12. Nørgaard, J.Q.H.; Andersen, T.L.; Burcharth, H.F. Wave loads on rubble mound breakwater crown walls in deep and shallow water wave conditions. Coast. Eng. 2013, 80, 137-147. [CrossRef]

13. Van Gent, M.R.A. Report H3608. Physical Model Investigations on Coastal Structures with Shallow Foreshores; 2D Model Test with Single and Double-Peaked Wave Energy Spectra. Available online: https://repository. tudelft.nl/islandora/object/uuid:1b4729de-2e86-4b8a-98d5-48d8e07d5902?collection=research (accessed on 26 January 2020).

14. Van Gent, M.R.A. Wave Run-Up on Dikes with Shallow Foreshores. Int. Conf. Coast. Eng. 2001, 127, 2030-2043. 
15. Mares-Nasarre, P.; Argente, G.; Gómez-Martín, M.E.; Medina, J.R. Overtopping layer thickness and overtopping flow velocity on mound breakwaters. Coast. Eng. 2019, 154, 103561. [CrossRef]

16. Herrera, M.P.; Medina, J.R. Toe berm design for very shallow waters on steep sea bottoms. Coast. Eng. 2015, 103, 67-77. [CrossRef] 